\title{
International cooperation on financial market regulation
}

\author{
Michael Abendschein ${ }^{1,2}$ (D) Harry Gölz ${ }^{3}$
}

Accepted: 17 May 2021 / Published online: 16 July 2021

(c) The Author(s) 2021

\begin{abstract}
At the latest the global financial crisis has raised the awareness of the need for a globally coordinated financial market regulation. Even though the necessity to cooperate is widely acknowledged, cooperation is often limited in practice. This article characterizes the formation of self-enforcing international financial regulation agreements. Our analysis allows to evaluate the desirability and feasibility of cooperative solutions and explains the challenges associated with the process of cooperation. We model the cooperation of national financial regulators in a game-theoretical framework that considers financial stability to be an impure public good. Joint national supervisory effort is supposed to increase aggregate welfare in terms of a more stable financial system both on a global and on a local level by simultaneously generating incentives to free-ride. Our analysis in general indicates the difficulty of reaching a fully cooperative solution. In our basic version of the model we show that partial cooperation of two or three countries is stable and improves the welfare of all countries relative to the non-cooperative Nash equilibrium. Further analyses highlight the role of additional club benefits. When signatory countries of a coalition gain benefits over and above the joint welfare maximization, stable coalitions of any size become feasible.
\end{abstract}

Keywords Financial Stability · International Policy Cooperation · Bank Regulation · Non-Cooperative Game · Impure Public Good

JEL Classification C72 - F53 - G18 · H87

The views expressed in this paper are those of the authors and do not necessarily reflect the views or policies of the Organisation for Economic Co-operation and Development.

Michael Abendschein

michael.abendschein@oecd.org

Harry Gölz

harry.goelz@uni-osnabrueck.de

1 Chair of Banking and Finance, Osnabrück University, Katharinenstr.7, 49074 Osnabrück, Germany

2 Present Address: Organisation for Economic Co-Operation and Development (OECD), 2 rue André Pascal, 75775 Paris Cedex 16, France

3 Chair of Public Economics, Osnabrück University, Rolandstr. 8, 49078 Osnabrück, Germany 


\section{Introduction}

Modern financial markets are to an increasing extent characterized by cross-border linkages between banks from various countries. Growing capital flows or crossborder asset and debt positions as well as the ongoing emergence of multinational banking groups that operate across the globe have shed light on the necessity to coordinate regulatory oversight across different countries. As a consequence of the great financial crisis in 2007-09 policy makers and regulators have been forced to increase efforts to harmonize and coordinate common regulatory actions in order to strengthen the resilience of the global financial system. In practice, however, the number of bi- or multilateral supervisory agreements between national regulators is still limited, see Beck et al. (2019).

Our work is inspired by the need for a better understanding of regulatory cooperation. We characterize the formation process of self-enforcing supervisory cooperation and evaluate the feasibility and efficiency of cooperation. Our analysis provides novel insights into the difficulty of reaching a stable outcome by explicitly determining the number of countries being willing to cooperate. We show that in equilibrium a partial cooperative solution where only a fraction of countries jointly set regulatory standards and partly internalize the positive externalities from supervision can be stable.

We analyze endogenous coalition formation by applying a two-stage game from cartel theory developed by D'Aspremont et al. (1983). We prove for the basic version of the model that the number of countries forming a stable regulatory coalition is at most three, depending on the specific functional specification. Furthermore, we highlight the crucial role additional club benefits might play and prove that larger coalitions are stable up to the grand coalition if they are taken into consideration; that is signatory countries of a coalition gain benefits over and above the joint welfare maximization. Such benefits can materialize in various forms, for instance through facilitated market access, more and faster information exchange and through reduced costs due to more adequate regulations adapted to the specific needs of the signatories. Similarly, such benefits can also be interpreted in negative terms when non-cooperation is penalized for example with respect to anti-money laundering.

In line with the seminal paper from Dell'Ariccia and Marquez (2006) that studies cooperation and competition among regulators, we are also able to explain the economic rationale for regulatory cooperation given that individual welfare maximization on the country level leads to insufficiently low levels of contributions to global financial stability. In our model, we can show how the stability of the financial system, which is induced by regulations on the country level and operationalized in form of the so-called supervisory effort, can be increased when regulators coordinate their supervisory actions. Still, the difficulty of reaching stable coalitions is also highlighted and explained by free-riding incentives of individual countries.

In this work, we argue that efforts to coordinate joint regulatory policies resemble problems that have been put forward in the framework of public good analyses. The public good character of financial regulation has firstly been mentioned in White (1994) but has fallen into oblivion for a long time. More recently, Gaspar and Schinasi (2010), 
VanHoose (2016) or Agénor and Pereira da Silva (2018) have come up again with this idea, stressing the need to view and analyze supervisory cooperation by explicitly taking global externalities from national regulatory tools and efforts into account. Micro- and macroprudential tools such as minimum capital adequacy ratios or a deposit guarantee scheme imposed by a national regulator shall increase the stability of the respective domestic banking system through reduced incentives for risk-taking. Such efforts to sustain financial stability on the national level, however, translate into positive externalities within other countries that are interconnected via their respective financial system. Thus, there exists a social rationale to cooperate in safeguarding financial stability by national authorities which could lead to an increase of global financial stability, as brought forward for example by Dell'Ariccia and Marquez (2006) and Gaspar and Schinasi (2010).

On the contrary, however, incentives of national regulators to reduce risk-taking within their financial system is normally restricted by efforts to maintain or increase the competitiveness of their banking system, in particular when financial globalization is far reaching and domestic banks are deeply embedded in international competition. Higher risk leads to negative externalities in form of a destabilization of the international financial architecture, which may lead to banking failures or large economic downturns worldwide. Banks in countries with lax financial market regulation do not have to pay for taking higher risk positions and therefore obtain an implicit subsidy, as noted by White (1994). Hence, national regulators have to impose a certain level of supervisory effort that takes the trade-off between financial stability on the one hand and the banking system's performance on the other hand into account, see for example Dell'Ariccia and Marquez (2006).

In our view and in the work of Kaul et al. (1999) international financial stability is non-rivalrous and partly non-excludable and can be interpreted as an impure international public good. Thus, if all countries that participate on global financial markets cooperate, social welfare in the involved countries will increase considerably. However, an increase of prudential supervision and regulation in a few countries leads to free-riding behavior of the remaining countries.

Early incentives to cooperate with respect to financial regulation were brought forward in the early 1970s when amounts of capital traded on euro markets increased drastically and the failure of the small German Herstatt Bank sent shock waves across the global financial markets, see Goodhart (2011). Consequently, several industrialized countries founded the Basel Committee on Banking Supervision (BCBS), which was meant to serve as a platform to discuss common regulatory incentives and reforms. Soon discussions started that aimed at creating a level playing field with respect to capital requirements induced by the Latin-American sovereign crises in 1982. Hence, the Basel Accord (Basel I) was a first important international financial regulation agreement (IFRA) with a view to reduce the implicit subsidy of domestic banking systems (Sinn 2003). The Basel Accord sets some voluntary standards that can only be understood as recommendations for all participating authorities. In recent work, Beck et al. (2019) collect data on supervisory cooperation worldwide and find more than 4000 agreements between individual countries. Their data reveals that the number of regulatory agreements is increasing but that only a small fraction of all potential agreements is realized. 
Supervisory cooperation today can have various forms, from unbinding standards such as the Basel agreements up to formally and legally binding regulatory unions such as within the European Union or the West African Economic and Monetary Union. Multilateral cooperation is often accompanied by several, partly interlinked international bodies that aim at reinforcing cooperation. Such is the case for example with respect to financial stability at the Financial Stability Board, with a focus on developing common market infrastructure standards at the Committee on Payments and Market Infrastructures (CPMI) or the International Organisation of Securities Commissions (IOSCO), or with a focus on common actions against money laundering on behalf of the Financial Action Task Force (FATF).

Therefore, it is important to understand the drivers and incentives of countries to follow such voluntary regulations. Negotiations, for instance between American, European and Asian regulators, do regularly take place. They partly result in common binding standards while other issues remain disputed resulting in different regulatory approaches that could undermine the common goal of global financial stability. Beck et al. (2019) highlight the importance of costs and benefits from regulation. They also show that a large fraction of countries only cooperates with a small amount of other countries, hence the coalition size can often be assumed to be small.

Against the background of various forms of regulatory cooperation to date, our approach is twofold. In the first place, we set up a stylized model of international supervisory cooperation that predicts a small number of cooperating countries. As a second step, we then introduce a mechanism to allow for a larger cooperation. While we do not aim at synthetically replicating and explaining a specific real-world agreement, this procedure enables us to study fundamental characteristics of cooperation that might help explaining different forms of observable supervisory cooperation. More precisely, we model financial stability as an international impure public good within a multi-country model and assess the role cooperation might play to assure a stable global financial system. We endogenously determine the number of signatories by studying a game theoretical model of international cooperation that explicitly takes costs and benefits from regulation for each single country into account. A stylized fact of competition between national supervisors is incorporated in our model by assuming that costs from regulation on a national level increase when other countries reduce their supervisory effort and vice versa, since a lower level of supervision abroad is directly interpreted as a competitive advantage compared to the more severely regulated national banking system. This setting allows us to assess how efficient the formation of an IFRA is in improving social welfare relative to the fully non-cooperative Nash equilibrium and the social optimal solution.

We show that partial cooperation leads to higher levels of supervisory effort on average and, hence, to a more stable financial architecture. Even though the signatory countries of the IFRA have to bear the additional regulatory efforts and costs, our results reveal that partial cooperation of two countries is stable for most of the feasible parameter space. Then, there is a distinct Pareto-improvement from partial cooperation relative to the non-cooperative Nash equilibrium. We furthermore confirm our results by studying the model under a different functional specification and find that coalitions of up to three countries might be feasible, irrespective of an additional assumption regarding parameter values. 
Our analysis also reveals that club benefits are of utmost importance when larger coalitions are desired. Whenever signatories of a regulatory coalition are exposed to additional benefits that go beyond the internalization of externalities, stable coalitions of any size can become feasible.

Two main implications can be drawn from these results. On the one hand, our model can confirm early empirical evidence that suggests that supervisory cooperation often materialize only within small groups of countries. This finding is particularly strong when gains from cooperation are small compared to involved costs (see Beck et al. (2019), and also for an analysis of the assumed underlying drivers). On the other hand, by confirming the necessity to cooperate with respect to regulatory actions, we can additionally show that the incorporation of club benefits is an important tool to overcome difficulties when aiming at the formation of larger stable supervisory coalitions.

The remainder of the paper is organized as follows: After the introduction of the research topic we discuss related literature in Sect. 2. In Sect. 3 we present the baseline model, explain the underlying assumptions and analyze the desirability of cooperation by comparing the non-cooperative Cournot-Nash equilibrium with the socially optimal solution. Subsequently, in Sect. 4 we examine the feasibility of IFRAs. First, we analyze the formation process of an IFRA with respect to an exogenously determined coalition size before we endogenously solve for the number of signatories. Then we add the notion of a club benefit and analyze its impact on coalition formation. In order to analyze whether our chosen functional specification drives the results, we solve the model with a different functional specification before we discuss the implications of our results in Sect. 5. Concluding remarks will be presented in the final section.

\section{Related literature}

The theoretical analysis of international financial stability plays an accretive important role in the economic literature. Allen and Gale (2004) describe the fundamental trade-off between financial stability on the one hand and the competitiveness of the banking industry on the other hand, similarly to Sinn (2003) who notices that national financial regulation creates a positive externality for foreign lenders, which leads to a low provision of regulation. Schoenmaker (2011) points to the same direction by interpreting financial stability, national financial policies and the global integration of financial markets as a trilemma whose aims cannot be jointly achieved.

While analyzing incentives to and outcomes of cooperation is relatively novel in the finance literature, it has a longstanding tradition in the area of public economics. VanHoose (2016) notes that similar problems of cooperation have already been extensively studied in the fields of fiscal policy, trade agreements or monetary policy and that potentially fruitful techniques and results developed so far are only slowly getting attention in the finance literature. Moreover, he indicates that the decision whether to cooperate in regulating financial markets appears to be very similar to research that has been conducted in the area of industrial organization for a long time. He argues that besides early work of White (1994), few efforts have been made 
to connect models and techniques from cartel theory to the obvious analogous of financial regulation cooperation.

This issue is most directly addressed in Gaspar and Schinasi (2010) who interpret financial regulation as a public good and suggest to rigorously apply models and techniques of the widely used toolbox of standard public economics. They apply the economic theory of alliances from Olson und Zeckhauser (1966) and the private provision of public goods model from Bergstrom et al. (1986) and compare the non-cooperative Nash equilibrium with the fully cooperative equilibrium. It turns out that the Nash equilibrium is characterized by an underprovision of financial stability since positive externalities of each individual regulator's effort to preserve financial stability is not accounted for in their utility functions. Additionally, they state that increasing cooperation is beneficial for all countries. They further introduce the notion of financial stability being an impure public good because benefits from regulation are assumed to differ on a global and on a local level. They can show that regulatory cooperation could be established in such a framework and state that the intensity of cooperation depends on the share of public and country specific benefits. However, due to the considerable amount of restricting assumptions, they admit that the feasibility of such cooperation is unclear.

A more thorough analysis of the conflicting incentives a national regulatory authority faces is conducted in the seminal work of Dell'Ariccia and Marquez (2001, 2006). ${ }^{1}$ Their model contains a representative bank per country, which is able to grant loans to domestic or international customers. Each bank is supervised by their domestic supervisor whose utility depends on the stability of the financial system on the one hand and the economic prosperity of its domestic bank on the other hand. Hardy and Nieto (2011) further develop the model from Dell'Ariccia and Marquez (2001) by explicitly incorporating a deposit guarantee scheme. Here, regulators can choose both a level of prudential supervision and the coverage of a deposit guarantee scheme. The latter decreases the costs that occur during a crisis while at the same time it increases the probability of a crisis by assuming incremental risk taking of banks. This feature is motivated by empirical work of Demirgüç-Kunt and Detragiache (2002) and Barth et al. (2006) who find excessive risk-taking by banks due to moral hazard when they can rely on large deposit guarantee schemes.

The set-up of Dell'Ariccia and Marquez (2006) and Hardy and Nieto (2011) allows to study the cooperation of national regulators. Dell'Ariccia and Marquez (2006) find that it is indeed hard to establish sustainable cooperation, in particular in a multi-country setting with heterogeneous countries. Even though the focus of their model is rather on banks' decision making and the financial cross-border linkages and to a smaller extent on cooperation, they find that a supranational institution is more likely to be formed by homogeneous countries. In a two-country setting, their results show that capital requirements in a common regulatory regime must be higher than in each individual country in order to incentivize both regulators to join

\footnotetext{
1 An early, reduced version of their model is presented in Dell'Ariccia and Marquez (2001) which is used as a reference by some authors such as Hardy and Nieto (2011), while Dell'Ariccia and Marquez (2006) contains a more complete and more complex version of their model.
} 
the cooperation. In this case, a two-country coalition is stable. However, in a multicountry setting, incentives to free-ride increase with the number of countries and they show that there are always countries that prefer to stay outside of an agreement. In the presence of a deposit guarantee scheme, the model of Hardy and Nieto (2011) shows in a two-country setting that cooperation leads to higher levels of supervision and lower levels of deposit insurance compared to the non-cooperative case. They can show that a joint regulation with respect to prudential supervision and a national deposit guarantee scheme leads to a more efficient outcome compared to the fully non-cooperative setting but that additional cross-country cooperation with respect to deposit insurance could further enhance the efficiency of financial regulation. However, their work mostly remains silent with respect to the requirements or conditions necessary to establish and sustain such cooperation.

Eldridge et al. (2015) extend the model of Dell'Ariccia and Marquez (2006) by assuming two countries that only differ in their market size. They find that smaller countries have a greater incentive for lax supervision. Park and Kim (2018) also extend Dell'Ariccia and Marquez (2006) by formalizing the assumption that banks possess political influence. Within their setup, the likelihood of cooperation depends on the specific characteristic of regulatory effort being a strategic substitute or complement. Kara (2016) studies a two-country model with potentially asymmetric countries and finds that cooperation often increases aggregate welfare. The outcome of his model predicts on the one hand that cooperation among countries that are heterogeneous with respect to few characteristics is harder to establish than among homogenous countries. On the other hand, in case countries differ with respect to several characteristics, cooperation might be facilitated as well. There is little empirical work that covers aspects of regulatory cooperation with Beck et al. (2019) as a remarkable exception. They conduct a comprehensive study to evaluate the existence and stability of regulatory cooperation worldwide. They find that the intensity of cooperation is correlated with potential cooperation gains. These gains mainly stem from externalities which represent benefits and costs of cooperation.

Common to most of the research in this field is the finding that non-cooperation of national regulators leads to the provision of an inefficiently low level of regulation, such that the need for an international cooperation or the formation of a supranational regulatory institution could be supported. However, it remains unclear how to impose sustainable cooperation. Agénor and Pereira da Silva (2018) give an excellent overview on recent literature with respect to regulatory cooperation. They conclude that most papers suggest that cooperation increases social welfare, but that it is hard to quantify these gains correctly and to establish true cooperation in practice. More precisely, they criticize that most theoretical models only consider two countries while it might be harder to establish cooperation in the more realistic scenario with several countries.

While most of the research suggests that regulatory cooperation on the international level is desirable with respect to global financial stability, some authors postulate a more differentiated view. Gehrig (2014) suspects a uniform global regulation to result in uniform bank business models that lead to increasing systemic risk. Based on the local information hypothesis which states that geographic location or distance is an important factor for banks' operations (see for instance Degryse 
and Ongena (2005) and Hauswald and Marquez (2006)), his model suggests that banks can choose whether to be regulated by a supranational or a local regulator. While global banks are better off by choosing the global regulator, local banks can profit from the superior information of their domestic regulator. While the problem could be solved by full information exchange between local and global regulators, Holthausen and Rønde (2005) show that such exchange is indeed hard to establish. More recently, Korinek (2017) presents a general equilibrium model that allows to determine if cooperation is beneficial. He emphasizes that cooperation is only advisable in case a non-cooperative equilibrium is Pareto-inferior to the cooperative equilibrium. Under a set of restricting assumptions, he argues that the non-cooperative Nash-equilibrium can be Pareto-efficient and potential spillovers turn out to be pecuniary externalities.

This work mostly relies on the work of Dell'Ariccia and Marquez (2006), Gaspar and Schinasi (2010) as well as Barrett (1994). We refrain from modelling bank's decision-making by studying the incentives of regulators to cooperate. We can show that the results of our model are in line with the predictions of Dell'Ariccia and Marquez (2006). However, we explicitly take the (impure) public good character of financial stability into account and rigorously apply techniques that have only been sketched by Gaspar and Schinasi (2010). This procedure allows us to model the decision of individual regulators to form or join a coalition endogenously. Our set up builds upon the canonical work with respect to international environmental agreements by Barrett (1994) and takes the impure public good modelling by Finus and Rübbelke (2013) as a starting point, before being adjusted in order to account for specific features of regulatory cooperation and competition.

This work contributes to the literature by studying the prerequisites of establishing and sustaining international regulatory cooperation and by explicitly examining the number of countries that are willing to form a cooperative coalition. We use straightforward modeling techniques that have proven to be useful in related fields but that have not been employed in this strand of the literature so far. Our work features some useful and realistic aspects that allow for a transparent interpretation of results against the background of empirical observations. Contrary to Hardy and Nieto (2011) we consider a multi-country setting in order to allow for a more realistic interpretation of our results since regulatory cooperation is normally set up between several countries. By introducing countries' decision to sign an agreement as an additional stage of the game, our work also goes one step further than Dell'Ariccia and Marquez (2006). We explicitly model the formation of an agreement and are thus able to determine the number of countries within a cooperation endogenously. We can further show how the intensity of cross-border externalities influences the amount of countries being willing to cooperate. Our model is enhanced further with the novel introduction of additional club benefits of different magnitude. The effects of club benefits within the model seem to strengthen our view that their notion is necessary when thinking about regulatory cooperation. Consequently, our work allows to gain valuable insight on how to influence policies that are meant to increase global financial stability. This will also lead to a better understanding of empirical results that show that regulatory coalitions can actually materialize in various intensities. Our work lies at the intersection of financial and 
public economics by applying tools from industrial organization and environmental economics to a current topic with respect to financial regulation.

\section{The model of financial stability as an impure public good}

\subsection{Assumptions}

We investigate the incentives of countries to regulate their domestic banks by analyzing countries' benefits and costs of financial regulation. We consider a world of $N \geq 2$ ex-ante symmetric countries, indexed $i=1, \ldots N$. All countries are interconnected on global financial markets. By assumption all countries have an incentive to sustain financial stability and thus supply supervisory effort. Like Hardy and Nieto (2011), this is our choice variable in the model. Alternatively, supervisory effort could be interpreted more directly as for example the capital adequacy ratio that is set by the regulator, see e.g. Dell'Ariccia and Marquez (2006). However, Agénor and Pereira da Silva (2018) note that it is difficult to ascribe the consequences of supervision to a distinct supervisory tool since there are always various tools simultaneously in use, be it micro-, macroprudential, or even monetary policy instruments. ${ }^{2}$ We employ a more general notion of supervisory effort such that our model can be applied to several different types of regulations, be it with respect to credit requirements, resolution forbearance or market infrastructure rules, just to mention a few.

We assume that financial market supervision constitutes an impure public good, as outlined in the following. Contrary to Dell'Ariccia and Marquez (2006) and in line with Dell'Ariccia and Marquez (2001) we take a reduced form approach and we abstract from the concrete loan and monitoring decision of banks. Instead of a rather general functional form as in Dell'Ariccia and Marquez (2001), we use a parametric model in order to be able to derive more specific results.

Each country $i$ obtains a benefit $B_{i}(\bar{q})$ from the supervision of all international financially connected countries, where $\bar{q}=\frac{1}{N} \sum_{i}^{N} q_{i}$ denotes average supervisory effort. We assume a quadratic public benefit function which is given by:

$$
B_{i}(\bar{q})=h \bar{q}-\frac{1}{2} \bar{q}^{2}
$$

where $h$ is a positive parameter. Thus, each country receives an equal share of worldwide supervisory effort which can be thought of e.g., as the implementation of capital requirements that are supposed to increase the stability of a single financial institution or, more generally, as the degree of prudence in the exercise of supervisory power. The reasoning is straightforward because a positive relation between supervisory effort and global stability is assumed. The more effort is undertaken in global terms, the more unlikely it becomes to experience financial crises. This translates

\footnotetext{
2 See also Acharya (2003) and Buck and Schliephake (2013) for an analysis regarding the interaction of different regulatory tools within the framework of a theoretical model.
} 
into shrinking expected negative implications for each individual country. A more stable financial system overall decreases the possibility for each bank and, hence, each country to be confronted with sudden bank failures that are caused by financial distress somewhere else.

Moreover, countries earn an extra exclusive benefit $D_{i}\left(q_{i}\right)$ from their individual supervisory effort which is given by:

$$
D_{i}\left(q_{i}\right)=h q_{i}-\frac{1}{2} q_{i}^{2} .
$$

It is suggestive that regulation on a national level increases in particular the stability of the respective country over and above the contribution of the overall system's stability for two main reasons. First, and following the literature (see e.g. Dell'Ariccia and Marquez (2006)), we assume home country regulation, which implies that a national regulatory authority oversees its own domestic banks only. ${ }^{3}$ One could argue that this assumption is not fully met with respect to well-known regulatory cooperation such as the Euro zone. However, we aim to set up a general model without referring to a specific regulatory set-up. Implications for our results in an alternative host country regulatory environment are discussed in Sect. 6. Given that domestic banks can be expected to have a larger market share in their domestic market, it can be assumed that the domestic financial system is particularly stable. This view is supported by the argument put forward in Gosh et al. (2017) who find that sound supervision on a national level reduces the risk of a country's financial system to be hit by shocks that stem from foreign financial shocks. Yet financial stability is often merely understood in global terms, there is still a reason to assume additional regional benefits.

As our model incorporates many features of the seminal model of regulatory cooperation presented in Dell'Ariccia and Marquez (2006), we will illustrate how our set-up builds upon their framework in the following. In our model, the regulator's welfare is on the one hand affected by the stability of the financial system. It is directly influenced by a supervisor's own strength of supervisory effort as well as the cumulative effort of the other supervisors. In the framework of their partial equilibrium model, Dell'Ariccia and Marquez (2006) similarly assume that financial stability constitutes one of the two drivers of a regulator's utility. Financial stability materializes by the monitoring effort that banks exert on behalf of their loan portfolio, which is directly influenced by capital standards set by their respective supervisor. More precisely, the utility of individual regulators depends on the stability of the financial system directly formalized by the (scaled) regulatory effort and on the other hand on the profitability of the banking system expressed by its cumulative profits achieved from lending activities. In our model, financial stability arises from supervisory efforts on the national level which enter our benefit function in Eqs. (1) and (2) as well as on the efforts of other regulators

\footnotetext{
3 See Park and Kim (2018) who assume host country regulation as an exception.
} 
additionally captured by Eq. (1). This results in a concave benefit function, similar to Dell'Ariccia and Marquez (2001).

The benefits stemming from bank profitability in Dell'Ariccia and Marquez (2006) are interpreted as costs of supervision in our model, because supervisory efforts directly lead to shrinking bank profits. Hence, instead of taking bank profits directly into account, we interpret the shrinking profitability as costs directly linked to supervisory effort that enter the payoff function of our regulator with a negative sign.

The downside of supervising domestic banks $C_{i}\left(q_{i}, \bar{q}\right)$ depends, in our model, on two elements.

$$
C_{i}\left(q_{i}, \bar{q}\right)=\frac{1}{2} c q_{i}^{2}+\theta\left(q_{i}-\bar{q}\right)
$$

where $c>0$ and $\theta>0$. The first part covers the direct costs of individual supervisory efforts that are modelled in a straightforward manner by a quadratic function. It captures the decline of banks' profitability due to costly regulatory constraints on the domestic level and thus only depends on individual effort. Here, our model mirrors the effects of the partial equilibrium model in Dell'Ariccia and Marquez (2006) where regulators set a specific capital adequacy ratio. The introduction or increase of a capital ratio decreases the amount of loans given by each bank and eventually decreases their profits. ${ }^{4}$

The second expression reflects the change in competitiveness of domestic banks. We assume that bank loans are imperfect substitutes for the consumers. Once again, an increase in the degree of supervisory effort on a domestic level will reduce the competitiveness of domestic banks when facing competition with less restricted foreign banks. A higher (lower) than average supervisory effort implies a loss (gain) in competitiveness of domestic banks. Here, we account for an effect similarly observable in Dell'Ariccia and Marquez (2006). In their model, the profitability of the domestic banking system does not only depend on the capital ratio set by their own domestic regulator, but also on the stringency of foreign regulators and, hence, on domestic bank's competitiveness with respect to foreign competitors. (Recall that by assumption, the capital requirements set by regulators can only be imposed upon their own domestic banks). Banks face a loan demand curve where consumers can choose between loans from domestic and foreign banks. The higher the capital ratio imposed upon domestic banks, the larger the share of loans originated by foreign banks on the domestic loan market. In our model, the second part of the cost function captures this competitiveness effect by assuming an additional benefit in case domestic regulation is weaker than the average abroad (reflecting the increasing profitability of the domestic banking sector abroad) and vice versa by assuming additional costs in case domestic supervisory effort is larger than in foreign markets.

\footnotetext{
4 See De Jonghe et al. (2020) and Uluc and Wieladek (2017) for a recent discussion on the relationship between supervisory effort and bank lending.
} 
To sum up, the assumed net benefit function of country $i$ is given by:

$$
\pi_{i}=\alpha\left(h \bar{q}-\frac{1}{2} \bar{q}^{2}\right)+(1-\alpha)\left(h q_{i}-\frac{1}{2} q_{i}^{2}\right)-\frac{1}{2} c q_{i}^{2}-\theta\left(q_{i}-\bar{q}\right),
$$

where $\alpha \in(0,1)$ is the public good factor of financial stability. If $\alpha=1$, financial stability would be a pure public good and if $\alpha=0$, it would be a private good. The functional specification we use here has also similarly been used by Barrett (1994) and Finus and Rübbelke (2013) in the literature on environmental treaty formation. The net benefit functions of all countries are assumed to be common knowledge and supervisory effort levels are freely observable by each country.

Finally, note that $\alpha$ and $\theta$ can be interpreted as proxies for the strength of financial cross-border activities and likewise as proxies for financial interconnectedness. The larger $\alpha$, the stronger a country depends on the efforts of foreign regulators to sustain financial stability because the own country depends to a great extent on global financial stability. This is often the case when countries are strongly active and interconnected on global financial markets. $\theta$ eventually expresses the degree of competition a country's banking system is exposed to regarding foreign banks. The more open financial markets are, the more (foreign) banks operate in a country and the stronger the degree of competitiveness shall be assumed. Thus, the stronger cross-border activities in the financial sector are assumed, the larger will be the effect of different regulatory regimes at home and abroad which translates into larger values for $\theta$.

\subsection{Cournot-Nash equilibrium}

In the non-cooperative Cournot-Nash game all countries choose supervisory effort simultaneously taking the effort levels of all others as given. In this case every single country simply maximizes its individual net benefit of supervisory effort and does not internalize the positive externalities. The maximization problem of each country $i$ is given by:

$$
\max _{q_{i}} \pi_{i}=\alpha\left(h \bar{q}-\frac{1}{2} \bar{q}^{2}\right)+(1-\alpha)\left(h q_{i}-\frac{1}{2} q_{i}^{2}\right)-\frac{1}{2} c q_{i}^{2}-\theta\left(q_{i}-\bar{q}\right) .
$$

The corresponding first order condition is given by:

$$
\alpha\left(\frac{h}{N}-\frac{\bar{q}}{N}\right)+(1-\alpha)\left(h-q_{i}\right)-c q_{i}-\theta\left(1-\frac{1}{N}\right)=0 .
$$

We solve Eq. (6) by using $\sum_{i}^{N} q_{i}=q_{i}+Q_{-i}$, where $Q_{-i}=\sum_{j \neq i} q_{j}$ in order to compute the best response function of country $i$, which is given by:

$$
q_{i}\left(Q_{-i}\right)=\frac{N(h(N+\alpha-N \alpha)+\theta-N \theta)-\alpha Q_{-i}}{N^{2}(1+c-\alpha)+\alpha} .
$$

$\partial q_{i} / \partial Q_{-i}<0$, which implies that the optimal effort choice of each country negatively depends on the aggregate effort level of all other countries. Concretely, this 
implies that a higher regulatory effort of one country is crowded out by the freeriding behavior of the others. Thus, effort levels are strategic substitutes. To compute the Cournot-Nash equilibrium we use the symmetry of the countries and solve Eq. (6) by inserting $\sum_{i}^{N} q_{i}=N q_{i}$. Individual and average effort quantities in equilibrium are given by:

$$
q_{u}=\bar{q}_{u}=\frac{h(N+\alpha-N \alpha)+\theta-N \theta}{N(1+c-\alpha)+\alpha}
$$

where index $i$ is replaced by $u$ indicating the non-cooperative Cournot-Nash solution. The partial derivatives are $\partial q_{u} / \partial h>0$ and $\partial q_{u} / \partial c, \partial q_{u} / \partial \alpha, \partial q_{u} / \partial \theta, \partial q_{u} / \partial N<0$. It is important to note that regulatory incentives decrease with the public good factor of financial stability $\alpha$ and the competitiveness factor $\theta$. Furthermore, the last partial derivative indicates the familiar finding that free-riding incentives increase with the amount of countries interconnected.

We summarize our main findings in Proposition 1 where the proof is given in the Appendix.

Proposition 1: For the Cournot-Nash equilibrium of the model specification given by Eq. (4), the following implications hold:

1.1 The more important the public good character of financial stability $\alpha$, the less willing is a country to contribute to regulation $\left(\partial q_{u} / \partial \alpha\right)$.

1.2 The more important the competitiveness $\theta$, the less willing is a country to contribute to regulation $\left(\partial q_{u} / \partial \theta\right)$.

1.3 Free-riding incentives increase with the number of countries $N$ interconnected on global financial markets $\left(\partial q_{u} / \partial N\right)$.

\subsection{Social optimum}

In order to evaluate the Cournot-Nash solution, we compare it to a socially desirable solution where all countries cooperate and hence all externalities are internalized. In the full cooperative outcome countries maximize aggregate net benefits of supervisory effort and solve the following maximization problem:

$$
\max _{q_{i}} \pi_{i}=\alpha\left(h \frac{N q_{i}}{N}-\frac{1}{2}\left(\frac{N q_{i}}{N}\right)^{2}\right)+(1-\alpha)\left(h q_{i}-\frac{1}{2} q_{i}^{2}\right)-\frac{1}{2} c q_{i}^{2}-\theta\left(q_{i}-\frac{N q_{i}}{N}\right) .
$$

The maximization problem in Eq. (9) is equivalent to the maximization problem where $\max _{q_{i}} \sum_{i=1}^{N} \pi_{i}$. Due to symmetric concave net benefits only a symmetric equilibrium is optimal. The corresponding first order condition is given by:

$$
\alpha\left(h-q_{i}\right)+(1-\alpha)\left(h-q_{i}\right)-c q_{i}=0
$$


and individual as well as average Pareto-efficient effort levels are given by:

$$
q_{o}=\bar{q}_{o}=\frac{h}{1+c}
$$

where index $i$ is replaced by $o$ in order to indicate the socially optimal solution.

Using the results above, we prove in the Appendix that $q_{o}>q_{u}$. Thus, countries are better off if they fully cooperate instead of choosing effort levels non-cooperatively. Furthermore, the degree of inefficiency determines the desirability of cooperation. We measure this with the difference $q_{o}-q_{u}$. Hence, cooperation is more beneficial the larger the effort gap between the Nash equilibrium and the social optimum. We show in the Appendix that this gap increases with the intensity of both externalities. They eventually create the rationale for cooperation in this model.

The economic intuition for this finding is clear. The parameters $\alpha$ and $\theta$ represent cross-border dependence as they measure the influence other countries exert on a single country. The larger $\alpha$, the more a single country depends on supervisory efforts on a global level. In such circumstances, financial stability is nearly a pure public good and hence the necessity to cooperate is evident. The case for $\theta$ is closely related. The larger it is, the stronger the competitiveness of domestic banks compared to foreign banks influences the utility function of a single country. In order to circumvent costly competition, it becomes more necessary to coordinate common regulatory actions that influence each country's bank profitability.

We summarize our main findings in Proposition 2.

Proposition 2: Comparing the Cournot-Nash equilibrium with the social optimum, the following implications hold:

2.1 Supervisory effort levels in the Cournot-Nash equilibrium are inefficiently low $\left(q_{u}<q_{o}\right)$.

2.2 The desirability of cooperation $\left(q_{o}-q_{u}\right)$ increases with the intensity of crossborder externalities $\alpha$ and $\theta$.

Proposition 2.1 confirms Proposition 1 of Dell'Ariccia and Marquez (2006). Proposition 2.2 is also in line with Dell'Ariccia and Marquez (2006) and additionally with the empirical findings of Beck et al. (2019). In what follows, we analyze a model version where partial cooperation is a possible outcome, which is in line with real world observations where cooperation is normally realized within a sub-group of countries.

\section{The model of an international financial regulatory agreement}

The model variant in Sect. 3 assumes that countries simply choose their effort levels and behave either non-cooperatively or fully cooperatively. In this chapter, we extend the basic model in three dimensions. In Sect. 4.1, we first modify the 
model by assuming that a cooperative coalition of given size plays Cournot-Nash against the free riders. In Sect. 4.2, we additionally endogenize the coalition size by assuming that countries are able to decide whether they want to become a signatory of a coalition or not. We further assume in Sect. 4.3 that signatories additionally gain exclusive club benefits.

\subsection{Partial cooperation of given size}

In this section we still assume a simultaneous game, but now an exogenously given coalition acts cooperatively by fully internalizing the external effects within the group. Hence, signatories maximize their joint net benefits whereas free riders maximize their own net benefits as before. We assume that there exist an exogenous number of $n \in\{1, \ldots N\}$ signatories and $N-n$ free riders. If $n=1$ the coalitional Nash equilibrium coincides with the ordinary Nash equilibrium in Sect. 3.2. If $n \geq 2$ a cooperating coalition is formed and the equilibria differ. A signatory country is denoted by subscript $s$ and a free rider country is denoted by subscript $f$. The free riders take the effort levels of all other countries as given and maximize their own net benefit by choosing the effort level unilaterally. The maximization problem of free riders is given by:

$$
\max _{q_{f}} \pi_{f}=\alpha\left(h \bar{q}-\frac{1}{2} \bar{q}^{2}\right)+(1-\alpha)\left(h q_{f}-\frac{1}{2} q_{f}^{2}\right)-\frac{1}{2} c q_{f}^{2}-\theta\left(q_{f}-\bar{q}\right) .
$$

The corresponding first order condition is given by:

$$
\alpha\left(\frac{h}{N}-\frac{\bar{q}}{N}\right)+(1-\alpha)\left(h-q_{f}\right)-c q_{f}-\theta\left(1-\frac{1}{N}\right)=0 .
$$

We solve Eq. (13) by using $\sum_{i}^{N} q_{i}=Q_{f}+Q_{s}$, where $Q_{f}=(N-n) q_{f}$ and $Q_{s}=n q_{s}$, in order to compute the aggregate best response function of free riders, which is given by:

$$
Q_{f}\left(Q_{s}\right)=\frac{(N-n)\left(h N(N-(N-1) \alpha)-(N-1) N \theta-\alpha Q_{s}\right)}{N(N(1+c-\alpha)+\alpha)-n \alpha} .
$$

$\partial Q_{f} / \partial Q_{s}<0$ implies that the optimal effort choice of free riders negatively depends on the aggregate effort level of the coalition.

The signatories of the coalition take the effort levels of all free riders as given and maximize their joint net benefits such that:

$$
\begin{aligned}
\max _{q_{s}} \pi_{s} & =\alpha\left(h\left(\frac{n q_{s}+(N-n) q_{f}}{N}\right)-\frac{1}{2}\left(\frac{n q_{s}+(N-n) q_{f}}{N}\right)\right) \\
& +(1-\alpha)\left(h q_{s}-\frac{1}{2} q_{s}^{2}\right)-\frac{1}{2} c q_{s}^{2}-\theta\left(q_{s}-\frac{n q_{s}+(N-n) q_{f}}{N}\right)
\end{aligned}
$$


The first order condition is given by:

$$
\theta\left(\frac{n}{N}-1\right)+(1-\alpha)\left(h-q_{s}\right)-c q_{s}+\alpha\left(\frac{h n}{N}-\frac{n\left(n q_{s}+(N-n) q_{f}\right)}{N^{2}}\right)=0
$$

We solve Eq. (16) by using $q_{s}=\frac{Q_{s}}{n}, q_{f}=\frac{Q_{f}}{N-n}$ and solve for $Q_{s}$ in order to get the aggregate best response of the signatories which is given by:

$$
Q_{s}\left(Q_{f}\right)=\frac{n\left(h N(N+n \alpha-N \alpha)+(n-N) N \theta-n \alpha Q_{f}\right)}{N^{2}(1+c-\alpha)+n^{2} \alpha} .
$$

Inserting (14) into (17) we get the total optimal effort level of the signatories $Q_{s}^{*}$ given by:

$$
Q_{s}^{*}=\frac{h n((n-1) n \alpha-(N(\alpha-1)-n \alpha)((1+c) N-(n+N-1) \alpha))-n(n-N)(-(1+c) N+(n+N-1) \alpha) \theta}{(1+c-\alpha)\left((1+c) N^{2}+(n-N)(n+N-1) \alpha\right)},
$$

where individual effort levels are $q_{s}^{*}=\frac{Q_{s}^{*}}{n}$. Inserting (18) into (14) we get the optimal aggregate effort level of the free riders given by:

$$
Q_{f}^{*}=\frac{(n-N)\left(h N^{2}(1+c-\alpha)(\alpha-1)+h(n-1) n(\alpha-1) \alpha+h N \alpha(\alpha-c-1)+(N-1) N(1+c-\alpha) \theta+(n-1) n \alpha \theta\right)}{(1+c-\alpha)\left((1+c) N^{2}+(n-N)(n+N-1) \alpha\right)} .
$$

Individual efforts of free riders are $q_{f}^{*}=\frac{Q_{f}^{*}}{N-n}$ and average effort levels are $\bar{q}=\frac{Q_{s}^{*}+Q_{f}^{*}}{N}$. By inserting all equilibrium effort levels into the payoff functions we receive the equilibrium payoffs of the signatories $\pi_{s}$ and free riders $\pi_{f}$.

We summarize our findings in Proposition 3 and the proof is given in the Appendix.

Proposition 3: For the coalition-fringe equilibria $(n \geq 2)$ of the model specification given by Eq. (4), the following implications hold:

3.1 Supervisory effort levels of signatories $q_{s}^{*}$ are higher and the effort levels of free riders $q_{f}^{*}$ are lower than in the Cournot-Nash equilibrium. Average effort levels are higher than in the Cournot-Nash equilibrium.

3.2 The effort levels of free riders $q_{f}^{*}$ are strictly decreasing in $n$ and the effort levels of signatories $q_{s}^{*}$ are increasing in $n$ if $\alpha \leq \frac{1}{2}$ or $c \geq 1$.

3.3 The net benefits of free riders $\pi_{f}$ are strictly increasing in $n$ and the net benefits of signatories $\pi_{s}$ are increasing in $n$ for $n>\sqrt{N}$.

3.4 The net benefits of free riders $\pi_{f}$ are strictly higher than the net benefits of signatories $\pi_{s}$.

From Proposition 3.1 we note that the higher efforts of the cooperating coalition are just partly crowded out by the lower efforts of the free-riding countries. Consequently, cooperative solutions increase aggregate financial stability even though free riders reduce their own efforts given a coalition of signatories. 
Proposition 3.2 shows that free-riding incentives of countries remaining outside the coalition increase when the intensity of cooperation increases. The more efforts are made by cooperating countries, the more financial stability is ensured, so that free rider countries increasingly have to implement less costly regulation of their own. On the contrary, if countries decide to cooperate they are in most cases rewarded by higher efforts of the other signatories. More precisely, that happens when $c$ is at least one or $\alpha$ is at most 0.5 . Whenever costs of regulation are high, the effort levels of signatories depend more on the number of signatories as countries are only willing to invest in costly regulation if they know that others do so, too. If regulation is cheap, incentives to conduct regulations are to a smaller extent influenced by other signatories. Similarly, whenever $\alpha$ is small and financial stability is rather a private than a public good, incentives to cooperate are weaker such that more regulatory efforts are only made if the other countries mirror this behavior as a country's intrinsic motivation to cooperate is limited.

Proposition 3.3 illustrates that signatories are in general better off when more countries cooperate as this implies a larger coordinated action to provide welfare increasing regulation. However, solutions exist for small $n$ when joining an agreement does not pay off. Simultaneously, free riders are always better off with an increasing number of signatories as this enlarges potential benefits from setting their own lower standards. Based on the given restricting assumptions, the net benefits of both types are increasing with the intensity of cooperation, which generally induces an incentive to cooperate. However, Proposition 3.4 reveals that there exists an incentive to stay outside the coalition because net benefits are strictly higher by staying outside.

These results illustrate countries' incentives for cooperation because with an exogenously given number of signatory countries all countries are better off with cooperation. However, they also reveal a potential difficulty to reach intensive cooperation, since incentives to free ride on the coalition's higher efforts exist. In the following section, we jointly analyze incentives to sign and to defect from a coalition by analyzing the stability of an agreement.

\subsection{Endogenous coalition formation}

We extend the model of Sect. 4.1 by assuming that countries have two decisions. First, they can choose to join a coalition, second, they choose their respective effort level. The additional choice to sign a cooperative agreement allows us to endogenize $n$. We concretely analyze the IFRA formation using a two-stage noncooperative game theoretical model which originates from the theory of industrial organization and is regularly applied in the literature on international environmental agreements. This model is well suited to analyze the incentives for cooperation in the absence of a supranational institution that is able to enforce binding regulatory measures. Hence, sovereign countries voluntarily sign a treaty to safeguard financial stability. Concretely, the IFRA formation consists of the following two stages: 
Stage 1: All countries simultaneously decide whether they want to become a signatory of the IFRA or not.

Stage 2: Cooperative signatories and non-cooperative free riders choose their effort levels simultaneously.

Stage 2 can be regarded as the effort choice subgame, which assumes a CournotNash structure as in Sect. 4.1. ${ }^{5}$ The entire game is solved via backward induction and the solution denotes a subgame perfect equilibrium.

We solve the game starting with the second stage, where free riders maximize their own net benefits and signatories maximize their joint net benefits taking the decisions with respect to $n$ as given. The solution of the subgame in stage 2 is equal to the solution of the model in Sect. 4.1. The difference, however, is that the outcomes of the effort subgame are the equilibrium payoffs of the signatories $\pi_{s}(n)$ and of the free riders $\pi_{f}(n)$ which depend on the endogenous variable $n$. The payoffs are needed in order to solve the first stage of the model. The solution concept, which is used to solve this stage, is based on D'Aspremont et al. (1983) and originates from the literature on cartel stability. According to this concept, an IFRA consisting of $n$ signatories is stable if:

$$
\pi_{s}(n) \geq \pi_{f}(n-1) \text { and } \pi_{f}(n) \geq \pi_{s}(n+1),
$$

where the first expression denotes the internal stability and the second expression the external stability condition. Internal stability means that no signatory country has incentives to withdraw from the agreement because the benefits within a cooperating coalition of given size $n, \pi_{s}(n)$ are larger or equal to the benefits when leaving the coalition and facing benefits $\pi_{f}(n-1)$ according to the diminished number of countries within the coalition, $n-1$. Similarly, external stability requires that free riders have no incentive to join the IFRA by assuming that all others stick to their decisions given that their benefits were reduced when entering the coalition. The equilibrium is achieved because the participation of one additional country would increase the total number of signatories and also signatories' level of effort. On the contrary, if a signatory withdraws from the IFRA, the remaining ones decrease their effort levels. This mechanism can be interpreted as a system of credible penalties and rewards. By applying the stability conditions, we are able to determine the absolute degree of cooperation. However, a small coalition can potentially be quite efficient when signatories increase their effort levels substantially. Therefore, we need a measure that is able to value the intensity of the welfare improvement of the partial agreement.

In order to assess the efficiency of the agreement further, we need to compare its performance with the social optimal and the non-cooperative outcome. Consequently, we use as a relative welfare measure, the "closing the gap index" (CGI), which was developed by Eyckmans and Finus (2006). The CGI $\in[0,1]$

\footnotetext{
5 In the literature on environmental agreements the Cournot-Nash variant is used by Finus and Rübbelke (2013), whereas Barrett (1994) assumes Stackelberg-leadership of the cooperating coalition.
} 
and measures the welfare enhancement due to the IFRA formation relative to the gap between the socially desirable situation and the situation where none of the countries cooperates. The total net benefit in case of treaty formation is given by $\Pi_{a}=n \pi_{s}(n)+(N-n) \pi_{f}(n)$. We get total payoffs in the social optimum $\Pi_{o}$ by inserting $n=N$ in $\Pi_{a}$ and we get total non-cooperative payoffs $\Pi_{u}$ by inserting $n=0$. The CGI is thus given by:

$$
C G I=\frac{\Pi_{a}-\Pi_{u}}{\Pi_{o}-\Pi_{u}} .
$$

When $C G I=1$, the IFRA is most efficient and is able to close the gap entirely. On the contrary, when $C G I=0$, the IFRA is fully inefficient and does not improve the situation at all.

We summarize our findings for this model variant in Proposition 4, with the proof given in the Appendix.

Proposition 4: For the self-enforcing agreement of the model specification given by Eq. (4), the following implications hold:

4.1 Two countries always cooperate in equilibrium when $N=2$. Two countries cooperate if $c \geq-1+\frac{\left(N^{2}+N-4\right) \alpha}{N^{2}}+\frac{2 \alpha \sqrt{3+(N-3) N}}{N^{2}}$ and otherwise the non-cooperative case is stable when $N \geq 3$.

4.2 Incentives to sign an agreement do not increase with the intensity of cross-border externalities $\alpha$ and $\theta$.

4.3 The CGI is invariant in the benefit parameter $h$ and in the competitiveness factor $\theta$.

4.4 The CGI converges to zero, if the number of countries $N$ becomes large.

Proposition 4.1 confirms the finding of Dell'Ariccia and Marquez (2006) indicating that the grand coalition of two symmetric countries is always stable if $N=2$. Moreover, we show that in the case of $N \geq 3$ a coalition larger than two can never be stable while a two-country coalition is stable for the parameter space specified above. A coalition of two countries is unstable only in the case of extreme parameter constellations with $\alpha$ being very large and $N$ and $c$ being very small. In particular in a situation with very low costs of supervision ( $c$ very low) and a high degree of freeriding ( $\alpha$ very large), entering a two-country coalition decreases welfare. As we have argued above, financial stability is clearly an impure public good, so $\alpha$ is likely to be not too close to one. In this case, each country supplies a considerable amount of supervisory efforts because it gains from financial stability without having to pay too much. Hence, coordinated actions to increase supervisory efforts are neither necessary nor worthwhile. This scenario, however, does not appear to be very plausible as costs to regulation can be assumed to be considerably different from zero. Proposition 4.1 is also related to Propositions 5 and 6 of Dell'Ariccia and Marquez (2006), but our results are more specific. We find that there always exists an incentive not to sign the grand coalition if $N>2$. We additionally note that a stable two-country coalition 
Fig. 1 The stability functions for internal and external stability are displayed for the given numerical example. The benefit of signatories and free riders depends on the number of signatories $\mathrm{n}$. There is only one interval where both functions take on positive values and, hence, $\mathrm{n}=2$ is the stable coalition size of this simulation

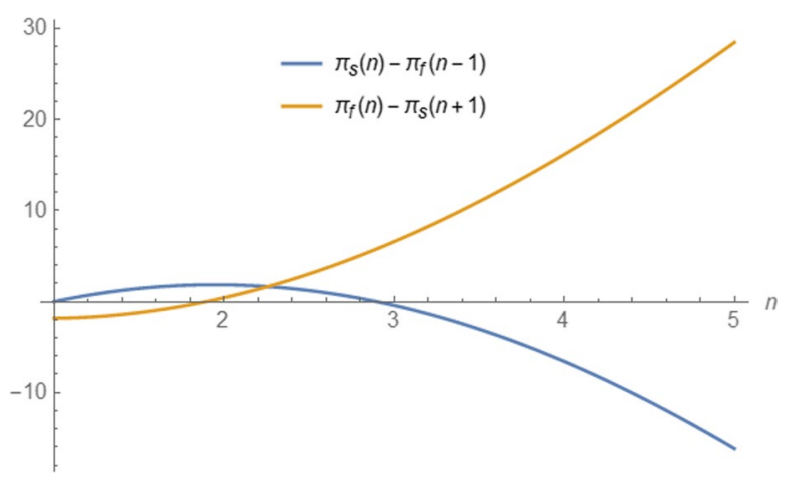

can break down when there are financial links with further countries, which complements Proposition 6 in their work.

From Proposition 4.2 we note that incentives to sign an agreement do not depend on the degree of excludability of financial stability. This result is in line with Finus and Rübbelke (2013), who find that additional private benefits of climate protection do not increase the incentive to sign a climate treaty. For our model, this implies that the private benefit on the national level stemming from financial regulation does not create further incentives to cooperate. Even though cooperation becomes more beneficial with higher $\alpha$, incentives to free-ride also increase. Incentives for cooperation do not depend on $\theta$ either. On the one hand, $\theta$ could have been expected to be a driver of cooperation as each country can be assured not to provide more regulatory effort than the other countries when all countries set a common level. On the other hand, $\theta$ reinforces incentives to deviate as it pays-off to undercut a common effort level. In our model, these two effects cancel each other out. Proposition 4.3 shows that the relative efficiency of an agreement of two countries does not depend on the competitiveness externality nor on the specific parametrization of the benefit function. Accordingly, the intensity of public benefits $\alpha$, the direct costs $c$ and the group size $N$ are the drivers of relative efficiency. Proposition 4.4 illustrates that the positive effect of a two-country agreement vanishes if $N$ is very large. This is a natural result as the effect of efforts to maintain global financial stability are marginal if only two countries jointly set common effort levels while simultaneously a very large number of countries free-rides. Still, this result highlights the suitability of our model in explaining characteristics of regulatory agreements.

In order to illustrate the solution procedure and the results of the membership stage we use a numerical example where the parameters are $c=2, \alpha=0.7, h=50$, $\theta=1$ and $N=10$. Figure 1 depicts the stability functions for this numerical example.

We see that there exists only one interval where both stability functions take on positive values and this interval only contains one integer which is $n=2$. Moreover, we further illustrate the numerical example in Table 1. The decision to join the coalition in this model is a one-shot decision, but it seems to be useful to think of it as a sequential decision. We first analyze the external stability condition beginning in the case where $n=1$ and none of the countries cooperates. A country decides to 
Table 1 The effort levels $q$ and resulting benefits $\pi$ from signatories and free riders conditional on the number of signatories $\mathrm{n}$ are displayed. The only situation where the benefit of a free rider $\pi_{f}$ does not increase when it joins the coalition and simultaneously the benefit of signatories $\pi_{s}$ does not increase when it leaves the coalition is when $n=2$

\begin{tabular}{lclll}
\hline$n$ & \multicolumn{1}{c}{$q_{s}$} & $q_{f}$ & $\pi_{s}$ & $\pi_{f}$ \\
\hline 1 & 7.43 & 7.43 & 288.6 & 288.6 \\
2 & 8.75 & 7.42 & 290.4 & 296.5 \\
3 & 10.03 & 7.4 & 296.1 & 312.1 \\
4 & 11.26 & 7.38 & 305.5 & 334.3 \\
5 & 12.41 & 7.35 & 318.2 & 362.3 \\
6 & 13.47 & 7.32 & 333.8 & 394.7 \\
7 & 14.43 & 7.28 & 352 & 430.3 \\
8 & 15.28 & 7.24 & 372.2 & 467.8 \\
9 & 16.03 & 7.19 & 393.9 & 506.1 \\
10 & 16.67 & - & 416.7 & - \\
\hline
\end{tabular}

join the coalition if the following payoff is higher than staying outside of the agreement. From Table 1 we see that $\pi_{f}(1)=288.6<290.4=\pi_{s}(2)$. Next, we assume that there are already two countries which have signed the IFRA. In this case $\pi_{f}(2)=$ $296.5>296.1=\pi_{s}(3)$ and, hence, there does not exist an incentive to enter a coalition of size three. Thus, the external stability is fulfilled for $n \geq 2$. Subsequently, we check when the internal stability condition holds and conduct the analysis in a situation where all countries fully cooperate. If the first country defects, it will get $\pi_{f}(9)=506.1>416.7=\pi_{s}(10)$ and the country decides to withdraw. It pays off for countries to withdraw whenever $n>2$. Thus, the only stable situation where both stability conditions are fulfilled is the case where two countries sign the IFRA.

The CGI for the numerical example is 0.053 . This implies that the agreement is able to close $5.3 \%$ of the gap between the fully non-cooperative and the social optimal case.

Furthermore, Fig. 2 shows the CGI depending on the cost parameter and the number of countries when $\alpha=0.7$.

The CGI obviously decreases in $c$ and $N$. If $N$ is very small the agreement consisting of two countries is relatively efficient. In case $c$ is close to zero, supervisory effort is rather cheap and the gap between the non-cooperative and the full cooperative case is very small. Figure 3 illustrates the CGI depending on the public good parameter and the number of countries when $c=2$.

Fig. 2 The relative efficiency of partial cooperation measured by the CGI is displayed for various simulated values of $\mathrm{c}$ and $\mathrm{N}$ with $\alpha=0.7$.

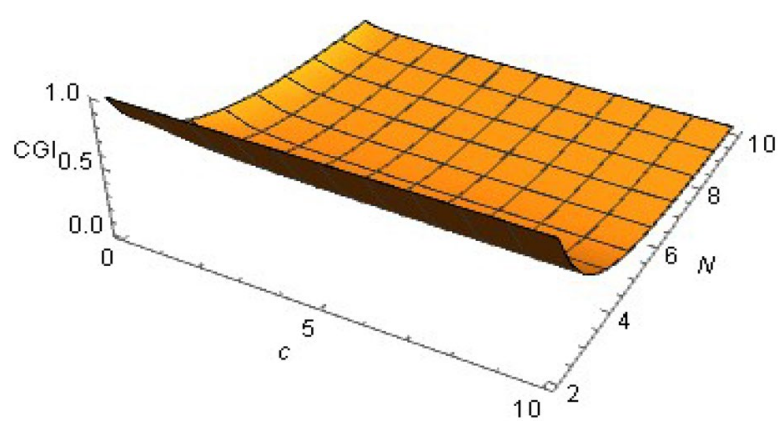


Fig. 3 The relative efficiency of partial cooperation measured by the CGI is displayed for various simulated values for $\alpha$ and $\mathrm{N}$ with $\mathrm{c}=2$

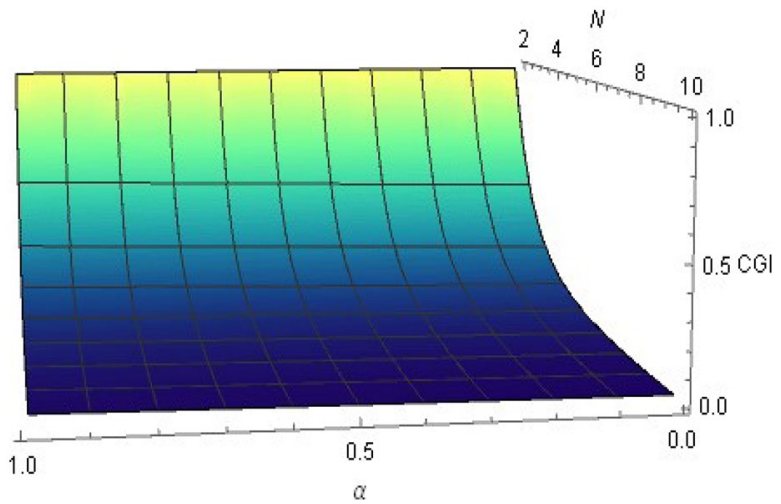

The CGI is slightly increasing in $\alpha$ even though the absolute degree of cooperation is constantly $n=2$. Hence, a cooperative agreement is most efficient when it is needed the most.

So far, our impure-public-good-approach is not fully able to explain all existing cooperative solutions regarding financial regulation, as it cannot give a rationale for multilateral cooperative arrangements such as the Basel Accords where many countries agree upon common standards. Henceforth, we extend our stylized model in the following section by taking into account an additional incentive mechanism that is relevant for real world negotiations.

\subsection{The model of an IFRA with exclusive club benefits}

We extend the model by assuming that signatories additionally earn an exclusive club benefit. Until now, the public good characteristic of financial regulation is understood to be transmitted via the increased system-wide stability due to each individual country's efforts to foster a resilient financial system. In addition, it is plausible to assume additional benefits for signatories of the coalition, for instance in terms of more efficient information sharing, better market access or simply an increased mutual trust among countries. Goodhart (2011) notes for instance that information asymmetries are expected to decrease in the framework of regulatory cooperation by reducing costs for participating regulators.

Club benefits often take the form of penalties in case of non-cooperation, too. (Financial) Market access in most economies assumes the compliance with specific regulations. It might be required to be part of a regulatory cooperation in order to be allowed to operate on certain markets. Within the European Union for instance, financial market access is conditional upon the equivalence of regulations such that non-EU financial institutions are only allowed to do business in the EU as long as the regulations in their home jurisdiction are to a major extent comparable to the ones in force in EU countries, see e.g. European Commission (2017). Money laundering is another field of action where non-cooperation is penalised, not least since terrorism financing has become a major policy concern. Being blacklisted by the Financial Action Task Force is a tool to penalise countries that are unwilling to meet 
certain standards with respect to anti-money laundering policies, see FATF (2020) that can in turn lead to an exclusion from the whole global financial system. Furthermore, even though it might ultimately not be necessary to be part of a regulatory coalition, it may nevertheless be beneficial given that only signatories are able to set or influence the regulations in force. Being part of a regulatory cooperation, hence, can facilitate market access and increases a country's banks profitability. From another perspective, this interpretation is equivalent to the notion of decreasing costs of regulation for those countries participating in regulatory cooperation. Nordhaus (2015) shows that so-called climate clubs, which are able to induce internal club benefits or external sanctions on free riders are fruitful for combating climate change. In line with Nordhaus (2015), Hoel and Schneider (1997) show that assuming private non-environmental costs increases the stable size of environmental agreements. Therefore, it can be expected that the results of our model are positively influenced by additional club benefits even though it might be challenging to quantify this effect in practice.

We assume the club benefit of a signatory country to be given by:

$$
E_{s}(n)=g(n-1) .
$$

For simplicity, this exclusive benefit is assumed to be a linear function of $n$. The only difference between this model version and the model presented in Sect. 4.2 is the benefit function of the signatories. The altered maximization problem of the signatories is given by:

$$
\begin{aligned}
\max _{q_{s}} \pi_{s}= & \alpha\left(h\left(\frac{n q_{s}+(N-n) q_{f}}{N}\right)-\frac{1}{2}\left(\frac{n q_{s}+(N-n) q_{f}}{N}\right)^{2}\right) \\
& +(1-\alpha)\left(h q_{s}-\frac{1}{2} q_{s}^{2}\right)+g(n-1)-\frac{1}{2} c q_{s}^{2}-\theta\left(q_{s}-\frac{n q_{s}+(N-n) q_{f}}{N}\right)
\end{aligned}
$$

where $g \geq 0$. We notice that the club benefit does not depend on effort and thus effort levels in equilibrium are not affected. The net benefits of the signatories solely increase with the amount of club benefits. Thus, the difference between payoffs of signatories and free riders decreases which determines the stable size of the coalition. This implies that the incentive to sign a treaty increases with the existence of club benefits. If we alternatively model external sanctions to free riding countries instead of club benefits to signatories, the payoffs of free riders are reduced by $g(n-1)$, whereas the payoffs of signatories do not change. This model would lead to the same results, because the payoff difference between signatories and non-signatories decreases equivalently.

In order to analyze the stability of the grand coalition, we note from Eq. (20) that it is sufficient to use the internal stability condition $\pi_{s}(N) \geq \pi_{f}(N-1)$, because there are no countries outside the coalition $(n=N)$. We prove in the Appendix that the grand coalition is stable if the club benefits are sufficiently large. The notion of club benefits also allows to extend the findings in Dell'Ariccia and Marquez (2006) where the grand coalition could not be stable. 
In order to measure the club benefits $E_{s}(N)$ required to stabilize the grand coalition we set them into relation to the amount of public benefits $H_{s}(N)$ which are given by:

$$
H_{s}(N)=\alpha B_{s}(N), \text { with } B_{s}(N)=\frac{h^{2}(1+2 c)}{2(1+c)^{2}}
$$

We use $\frac{E_{s}(N)}{H_{s}(N)} \equiv \gamma$ in order to have a more illustrative measure.

Proposition 5: For the model specification given by Eq. (4) including club benefits the self-enforcing IFRA has the following properties:

5.1 The existence of club benefits increases the stable size of a coalition and can even induce the grand coalition, if club benefits are sufficiently relevant.

5.2 The relation of club benefits to public benefits $\frac{E_{s}(N)}{H_{s}(N)}$ required in order to stabilize the grand coalition is strictly increasing in the competitiveness factor $\theta$ and strictly decreasing in the benefit factor $h$.

These are very important characteristics, since in practice we can observe regulatory cooperation including several countries. This result explains how club benefits could be an important driver to enlarge a stable coalition size over and above the pure internalization of externalities based on the public good characteristic of financial regulation. Proposition 5.2 gauges the relative size of the club good benefit $E_{s}(N)$ that is required to stabilize the grand coalition. We can see that stronger competition with other countries requires relatively larger club benefits to induce the grand coalition while larger values of the benefit parameter $h$ require a relatively smaller amount of club benefits.

We further illustrate how different magnitudes of club benefits influence the stable size of an agreement and how the existence of club benefits changes the influence of the other model parameters by using a numerical example. Figure 4 illustrates the stable size of a coalition depending on the public good parameter $\alpha$ and the club benefit using the same exogenous parameters values as in the previous simulation. First, we note that the coalition size $n$ increases in the amount of club benefits .

Second, we analyze if the existence of club benefits can alter the result that the coalition size is almost invariant in the public good parameter $\alpha$. With $g>0$ the size of the stable coalition decreases in $\alpha$. However, for a given value of $g$ the grand coalition $(n=N=10)$ is now stable for small values of $\alpha$. This is due to the fact that the amount of club benefits is relatively high in relation to public benefits in such a situation. Club benefits are hence most efficient when cooperation is not that beneficial. 
Fig. 4 The stable number of signatories $\mathrm{n}$ for various simulated values for $\alpha$ and $g$ are displayed. The yellow area represents the grand coalition with $n=N=10$

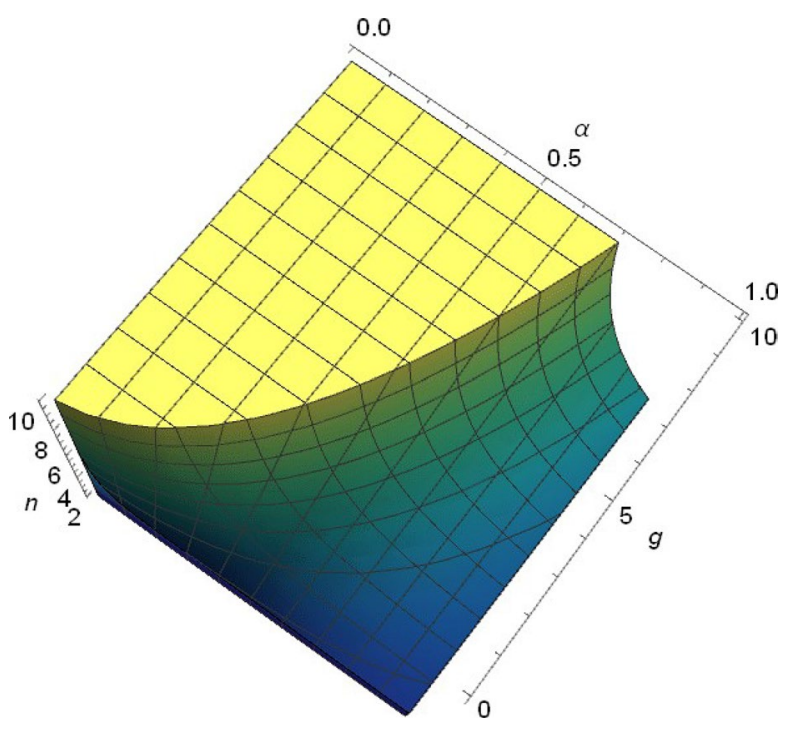

\subsection{Model version with linear benefit function}

Naturally, our theoretical model and the derived results depend to an important extent on the chosen set-up and the assumed functional specification. There is a trade-off between the necessary complexity of the modeling strategy and the generalization of results. So far, we have assumed a concave benefit function given that it is a realistic assumption that the marginal benefit from financial stability decreases. We advocate the view that it is desirable to assume a realistic set-up even though the complexity of the model might be considerably affected. However, this comes at certain cost because some interesting relations can only be formulated with the help of numerical illustrations. As an alternative, in this section we reduce the complexity of the model by assuming the linear benefit functions $B_{i}(\bar{q})=b \bar{q}$ and $D_{i}\left(q_{i}\right)=b q_{i}$. On the one hand, this increases the level of abstractness and eliminates some important features of the previous setting. On the other hand, it allows deriving more general, analytical results by eliminating the necessity to simulate parameter constellations. By comparing the predictions of the two model versions we are additionally able to evaluate whether the main results are driven by the used functional specifications.

The altered net-benefits are given by:

$$
\pi_{i}=\alpha b \bar{q}+(1-\alpha) b q_{i}-\frac{1}{2} c q_{i}^{2}+g(n-1)-\theta\left(q_{i}-\bar{q}\right),
$$

where $b>0$. Linear benefits are special because they imply that reaction functions are orthogonal such that there is no strategic interaction. We can show that the main effects and results of the previous model version are robust towards this alternative 
specification. We summarize the solution to the second stage in Lemma 1 with the proof given in the Appendix.

Lemma 1: Subgame perfect efforts and net benefits have the following properties:

1.1 The effort levels of free riders $q_{f}^{*}$ are independent of $n$ and the effort levels of signatories $q_{s}^{*}$ are strictly increasing in $n$.

1.2 The net benefits of free riders $\pi_{f}$ and signatories $\pi_{s}$ are strictly increasing in $n$.

Then we solve stage one where the solution is characterized in Proposition 6 and the proof is given in the Appendix.

Proposition 6: For the self-enforcing agreement of the model specification given by Eq. (25), the following implications hold:

6.1 If $g=0$, two or three countries always cooperate.

6.2 If $g>0$, depending on the amount of club benefits, coalitions from size three until the grand coalition exist. Incentives to cooperate strictly increase in $c$ and $N$ and strictly decrease in $\alpha$ and $\theta$.

6.3 The relation of club benefits to public benefits $\frac{E_{s}(N)}{H_{s}(N)}$ required in order to stabilize the grand coalition is strictly increasing in the competitiveness factor $\theta$ and the number of countries $N$ and strictly decreasing in the benefit factor $b$.

6.4 The CGI depends only on the number of countries $N$ if $g=0$ and depends on all $(N, n, b, \alpha, \theta)$ parameters if $g>0$. The CGI converges to zero, if the number of countries $N$ becomes large.

Proposition 6.1 is in line with our previous results where we show that a coalition of $n=2$ is stable for most parameter constellations. We see that this finding is not mainly driven by the assumed concave benefit functions, but that it is a robust finding for the assumed impure public good characteristic of financial stability. This is not very surprising since only extreme values come up with instable coalitions of size $n=2$. Proposition 6.2 shows that the introduction of club benefits can once again lead to a stable coalition of any size including the grand coalition. The linear model specification can even induce further insights. Here, it can be shown that incentives to cooperate are directly and unanimously influenced by several variables when club benefits are taken into account. On the one hand, an increasing number of countries and increasing costs of regulation lead to a larger coalition size, because free-riding does not counteract increasing benefits from cooperation. On the other hand, the more strongly regulation is interpreted as a public good and the stronger competition with other countries can be assumed, the smaller a cooperative coalition will be. 
The results of this section strengthen our view that large coalitions are indeed hard to establish but that at least small coalitions can be stable. The effect of a club benefit has similar implications as before and highlights a mechanism to explain coalitions over and above three countries.

\section{Discussion and relevance}

The theoretical results derived in this work confirm widespread consensus that cooperation among financial supervisors is necessary to maintain and increase financial stability. The (impure) public good modelling of financial stability allows the assessment of the feasibility and efficiency of cooperative agreements. The results achieved so far indicate that regulatory cooperation in general is not very stable and not very large with a maximum number of signatories of two to three in the baseline settings. This result might only be surprising on first sight. However, when regarding cooperation rates among regulators on a global scale, it turns out that large regulatory agreements with strict and binding rules for each signatory are indeed hardly existent. The work of Beck et al. (2019) highlights this finding in a very detailed comprehensive empirical investigation. They find that, globally, only a small fraction of potential regulatory agreements is achieved and in case they are, the number of signatories is often rather small. Our work lays a rationale for this finding by providing theoretical evidence for the difficulty of reaching larger coalition sizes. In addition, our results indicate that given the obvious necessity to cooperate, smaller regulatory coalitions are indeed feasible and stable.

In addition, this work points a way to explain larger coalition sizes that are partly observable as stated in Beck et al. (2019), where clearly more than two or three countries cooperate. Club benefits might play a prominent role in order to stabilize larger coalitions. In fact, our modelling approach remains necessarily rather abstract and we cannot account for each specific influence that might be relevant in practice. Therefore, it is a straightforward approach to assume additional benefits that arise conditional on forming a coalition that exceed pure simple benefits from global supervisory efforts. This is a way to break down and handle considerably more complex relationships between countries by still incorporating the most important effects into our model.

The relevance of club benefits for the stability and size of a regulatory cooperation can also be interpreted in a normative sense. Given that regulatory cooperation is at the agenda of policy makers worldwide, club benefits might provide a promising approach to reach larger agreements. It could be the task of future research to investigate potential club benefits in more detail and to analyze the effective channels. This could allow policy makers to more directly address specific options that might be incorporated into negotiations regarding future supervisory agreements. For the time being, it is important to accentuate that additional club benefits are not only a way to explain a cooperation of a given size but also a potential remedy to overcome obstacles in the coalition formation process.

While our model is mainly inspired by regulatory cooperation with respect to banks, there is no inherent model-specific feature that prevents us from extending 
it to cover non-bank regulations as well. However, we regularly contrast and align our findings with results from the literature, such as Dell'Ariccia and Marquez (2006) that studies regulatory competition due to bank lending mechanisms. We do not perform a similarly nuanced comparison with non-bank regulations such that further research in this area would be required.

Finally, the choice of a home country regulation setting where each national supervisor overseas its national banks irrespective of the jurisdiction they operate in could be seen as a crucial assumption. As an alternative, host country regulation could be taken into account where each national supervisor overseas each bank in its own jurisdiction, irrespective of a bank being national or foreign. On the one hand, our model crucially depends on the home country assumption as this is the starting point for using the public good framework, such that results are not directly conceivable with host country regulation. On the other hand, however, we note that our model captures underlying patterns and mechanisms from the "micro-founded" bank-level model from Dell'Ariccia and Marquez (2006) and we could show that the results of our aggregate model mirror theirs. Therefore, we are optimistic that our results are also somewhat robust to a host country setting, following the arguments put forward in their work. They argue that even though in a host country setting foreign bank subsidiaries are regulated based on the regulation in the country of operation, there is still a strong link to the mother branch in the home country. The quality and level of capitalization of the bank subsidiary in the host country abroad is still strongly linked to the level and quality of capitalization of the mother company in the home country, which is determined by their own regulator at home. Hence, the general drivers of our model can be assumed to persist to some extent.

\section{Concluding remarks}

The cooperation of national regulators appears to be imperatively important given the increasing interconnections on global financial markets. Not least can regulatory cooperation be regularly observed, for instance in a stricter form on behalf of the European Euro Zone, or in a less binding way in form of the Basel agreements. In this work the cooperation of national financial regulators is studied in a gametheoretical framework. The provision of financial stability in terms of the so-called supervisory effort by regulators is interpreted as an impure public good, since aggregate efforts across several countries increase the overall financial stability while a certain benefit materializes only on local level. The public good character of financial regulation, however, leads to noticeable incentives to free-ride. A laxer national regulation translates into a competitive advantage of the domestic banking system. Similar issues have been largely studied in the literature on environmental economics, where cooperation incentives of countries are analyzed by methods from industrial organization. Due to the similarities of the underlying global public good structure, we apply solution methods from industrial organization. More concretely, we study the incentives of regulators to form self-enforcing international regulatory agreements that might prevent free-riding and increase the overall global financial stability. 
Our approach enables us to determine the number of countries signing an agreement endogenously. We can show that partial cooperative solutions are feasible where, depending on the specific model set-up, at most two to three countries form a stable coalition. Without any further assumptions our baseline model predicts a low intensity of cooperation and cannot explain high degrees of cooperation. Therefore, we incorporate club benefits as an additional mechanism which might help to explain larger coalitions. Our analysis reveals that club benefits can raise the number of countries willing to cooperate significantly. This might point the way to policy makers aiming at increasing the size of self-enforcing regulatory agreements. Our results also confirm that cooperation is indeed desirable, since country-individual welfare maximization leads to an underprovision of financial regulation relative to a socially optimal situation where all countries jointly set regulatory standards. We show that full cooperation is hard to establish, and that potential free-riding behavior constitutes a real threat to joint efforts on a global level to maintain and improve financial stability. In general, those findings highlight the need to study how incentives of different national regulatory bodies might be aligned in order to increase the potential of common actions towards a more stable financial system.

Our model could be extended along various lines. It could be interesting to study how model parameters and results change when asymmetries among countries are considered. As asymmetric information on financial markets plays a huge role, it would be particularly important to analyze a model where one country or a group of countries has private information about costs or benefits of regulation. Moreover, it would be more realistic to assume multiple regulatory instruments in order to incorporate additional spillovers between them. A further extension could be to assume sequential effort decisions that allow studying potential first-mover (dis-) advantages. Additionally, the analysis of repeated interactions would be more realistic and could offer additional insights. So far, our model is designed to reflect typical characteristics of the formation of regulatory cooperation in general, without aiming at tracing a specific real-word agreement. An interesting further avenue of research could be to have a closer look on specific forms of cooperation, for instance on behalf of anti-money laundering, and to study the involved individual features in more detail.

Economic research has a long tradition in studying the effects of public goods and free-riding behavior and it is advisable to resort to solution concepts from these strands of the literature, since they seem to be able to give valuable insights that can be used for the analysis of financial stability as well. In this exercise, we apply an impure public good modelling to the topic of financial regulation. The rather general model could be a valuable starting point for ample different topics that deal with cooperation on behalf of impure public goods. 


\section{Appendix}

\section{Proof of Proposition 1}

$\partial q_{u} / \partial \alpha=-\frac{(N-1)(h c N+(N-1) \theta)}{(N(1+c-\alpha)+\alpha)^{2}}<0, \partial q_{u} / \partial \theta=\frac{1-N}{N(c+1-\alpha)+\alpha}<0$ and $\partial q_{u} / \partial N=-\frac{h c \alpha+\theta+c \theta}{(N(1+c-\alpha)+\alpha)^{2}}<0$.

\section{Proof of Proposition 2}

The difference $q_{o}-q_{u}=\frac{(N-1)(h c \alpha+\theta+c \theta)}{(1+c)(N(1+c-\alpha)+\alpha)}>0, \partial\left(q_{o}-q_{u}\right) / \partial \theta=\frac{N-1}{N(c+1-\alpha)+\alpha}>0$ and $\partial\left(q_{o}-q_{u}\right) / \partial \alpha=\frac{(N-1)(h c N+(N-1) \theta)}{(N(1+c-\alpha)+\alpha)^{2}}>0$.

\section{Proof of Proposition 3}

The individual effort levels of signatories are given by:

$$
q_{s}^{*}=\frac{h((n-1) n \alpha-(N(\alpha-1)-n \alpha)((1+c) N-(n+N-1) \alpha))-(n-N)(-(1+c) N+(n+N-1) \alpha) \theta}{(1+c-\alpha)\left((1+c) N^{2}+(n-N)(n+N-1) \alpha\right)},
$$

whereas the individual effort levels of free riders are given by:

$$
q_{f}^{*}=\frac{-h N^{2}(1+c-\alpha)(\alpha-1)+h N(1+c-\alpha) \alpha+h n \alpha(n-1+\alpha-n \alpha)-(1+c)(N-1) N \theta+(N-n)(n+N-1) \alpha \theta}{(1+c-\alpha)\left((1+c) N^{2}+(n-N)(n+N-1) \alpha\right)} .
$$

Inserting the equilibrium effort levels into Eqs. (12) and (15) we get the equilibrium net benefits given by:

$$
\begin{aligned}
\pi_{s}= & \left(h ^ { 2 } \left((1+c)^{2} N^{4}+(1+c) N^{2}(2(n-1) n+(2-3 N) N) \alpha+(n-N)\left(n+n^{3}+n^{2}(N-2)\right.\right.\right. \\
& \left.\left.+\left(c^{2}-3\right) n N^{2}+N\left(-1+\left(4+c^{2}(N-2)-3 N\right) N\right)\right) \alpha^{2}+(c-1)(n-N)^{2}(n+N-1)^{2} \alpha^{3}\right) \\
& +2 h c(n-N) \alpha\left((1+c) N^{2}(n+N-2)+(n-N)(n+N-1)^{2} \alpha\right) \theta+(1+c)(n-N)\left((1+c) N^{2}(n+N-2)\right. \\
& \left.\left.+(n-N)(n+N-1)^{2} \alpha\right) \theta^{2}\right) /\left(2(1+c-\alpha)((n-1) n \alpha+N(N(1+c-\alpha)+\alpha))^{2}\right)
\end{aligned}
$$

and

$$
\begin{aligned}
\pi_{f}= & \left(h ^ { 2 } \left(2 N^{3}(1+c-\alpha) \alpha(1+(c-1) \alpha)+(n-1)^{2} n^{2} \alpha^{2}(1+(c-1) \alpha)+2(n-1) n N \alpha^{2}(1+(c-1) \alpha)\right.\right. \\
& \left.-N^{4}(1+c-\alpha)(\alpha-1)(1+c+(c-1) \alpha)+N^{2}(1+c-\alpha) \alpha(\alpha-c \alpha+2(n-1) n(1+(c-1) \alpha))\right) \\
& -2 h c \alpha\left((1+c)\left(-2(n-1) n+(N-1)^{2}\right) N^{2}-(n-N)^{2}(n+N-1)^{2} \alpha\right) \theta-(1+c)((1+c)(-2(n-1) n \\
& \left.\left.\left.+(N-1)^{2}\right) N^{2}-(n-N)^{2}(n+N-1)^{2} \alpha\right) \theta^{2}\right) /\left(2(1+c-\alpha)((n-1) n \alpha+N(N(1+c-\alpha)+\alpha))^{2}\right) .
\end{aligned}
$$

If $n=1$ effort levels of signatories and free riders are the same and coincide with the non-cooperative Nash equilibrium. Hence, a comparison is only valid if $n \geq 2$. Assuming $n \geq 2$ the following effort level differences are given by:

$$
q_{s}^{*}-q_{c}=\frac{(n-1)\left((1+c-\alpha) N^{2}+N \alpha-n \alpha\right)(h c \alpha+\theta+c \theta)}{(1+c-\alpha)(N(1+c-\alpha)+\alpha)\left((1+c-\alpha) N^{2}+\left(n^{2}-n+N\right) \alpha\right)}>0,
$$




$$
q_{f}^{*}-q_{c}=-\frac{(n-1) n \alpha(h c \alpha+\theta+c \theta)}{(1+c-\alpha)(N(1+c-\alpha)+\alpha)\left((1+c-\alpha) N^{2}+\left(n^{2}-n+N\right) \alpha\right)}<0
$$

and

$$
\bar{q}-q_{c}=\frac{(n-1) n N(h c \alpha+\theta+c \theta)}{(N(1+c-\alpha)+\alpha)\left((1+c-\alpha) N^{2}+\left(n^{2}-n+N\right) \alpha\right)}>0 .
$$

Hence, $q_{s}^{*}>\bar{q}>q_{c}>q_{f}^{*}$ if $n \geq 2$.

$$
\partial q_{s}^{*} / \partial n=\frac{N\left(-n^{2} \alpha+N(N(1+c-\alpha)+\alpha)\right)(h c \alpha+\theta+c \theta)}{(1+c-\alpha)\left((1+c-\alpha) N^{2}+\left(n^{2}-n+N\right) \alpha\right)^{2}},
$$

is $>0$ for $n<\frac{\sqrt{N} \sqrt{N(1+c-\alpha)+\alpha}}{\sqrt{\alpha}}$ and $<0$ for $n>\frac{\sqrt{N} \sqrt{N(1+c-\alpha)+\alpha}}{\sqrt{\alpha}}$. Clearly $q_{s}^{*}$ is increasing in $n$ if $\frac{\sqrt{N} \sqrt{N(1+c-\alpha)+\alpha}}{\sqrt{\alpha}}>N$. Rewriting this condition, we get $c>-1+\alpha\left(2-\frac{1}{N}\right)$. This is fulfilled for $\alpha \leq \frac{1}{2}$ or for $c \geq 1$.

$$
\partial q_{f}^{*} / \partial n=-\frac{(2 n-1) N \alpha(h c \alpha+\theta+c \theta)}{(1+c-\alpha)\left((1+c-\alpha) N^{2}+\left(n^{2}-n+N\right) \alpha\right)^{2}}<0 .
$$

This means that the effort levels of the free riders strictly decrease in the number of cooperating countries.

$$
\partial \pi_{s} / \partial n=\frac{N^{2}\left((n-1) N^{2}(1+c-\alpha)+n^{3} \alpha-n N \alpha\right)(h c \alpha+\theta+c \theta)^{2}}{(1+c-\alpha)\left((1+c-\alpha) N^{2}+\left(n^{2}-n+N\right) \alpha\right)^{3}}
$$

is definitely $>0$ for $n>\sqrt{N}$ and $<0$ for $n<\sqrt{N}$.

$$
\partial \pi_{f} / \partial n=\frac{(2 n-1) N^{2}\left(N^{2}(1+c-\alpha)+\alpha\right)(h c \alpha+\theta+c \theta)^{2}}{(1+c-\alpha)\left((1+c-\alpha) N^{2}+\left(n^{2}-n+N\right) \alpha\right)^{3}}>0 .
$$

Assuming again $n \geq 2$ the difference of net benefits between free riders and signatories is given by:

$$
\pi_{f}-\pi_{s}=\frac{\left(n^{2}-1\right) N^{2}(h c \alpha+\theta+c \theta)^{2}}{2(1+c-\alpha)\left((1+c-\alpha) N^{2}+\left(n^{2}-n+N\right) \alpha\right)^{2}}>0 .
$$




\section{Proof of Proposition 4}

Inserting Eqs. (28) and (29) into the internal stability function $\pi_{s}(n)-\pi_{f}(n-1) \geq 0$ we get:

$$
\begin{gathered}
-\left(\left(( n - 1 ) N ^ { 2 } \left((n-3) N^{4}(1+c-\alpha)^{2}+2(n-1) N^{3}(1+c-\alpha) \alpha\right.\right.\right. \\
+(n-3)(n-1)^{2} n^{2} \alpha^{2}+2 n(-1+(n-2) n) N \alpha^{2} \\
+N^{2} \alpha(2(1+c)(-2+(n-3)(n-1) n) \\
\left.+(5+n(-5-2(n-4) n)) \alpha))(h c \alpha+\theta+c \theta)^{2}\right) \\
\frac{\left.\left(2(1+c-\alpha)\left((1+c) N^{2}+(n-N-1)(n+N-2) \alpha\right)^{2}\left((1+c-\alpha) N^{2}+\left(n^{2}-n+N\right) \alpha\right)^{2}\right)\right)}{}
\end{gathered}
$$

Inserting Eqs. (28) and (29) into the external stability function $\pi_{f}(n)-\pi_{s}(n+1) \geq 0$ we get:

$$
\begin{gathered}
\left(n N ^ { 2 } \left((1+c)^{2}(n-2) N^{4}-2(1+c) N^{2}\left(2-(n-2) n(1+n)-n N+(n-2) N^{2}\right) \alpha\right.\right. \\
+(1+n-N)(-4 N+(n+N)((n-2) n(1+n) \\
\left.\left.\left.\left.+(2+n) N-(n-2) N^{2}\right)\right) \alpha^{2}\right)(h c \alpha+\theta+c \theta)^{2}\right) \\
\frac{\left.\left(2(1+c-\alpha)\left((1+c-\alpha) N^{2}+\left(n^{2}-n+N\right) \alpha\right)^{2}(n(1+n) \alpha+N(N(1+c-\alpha)+\alpha))^{2}\right)\right)}{2} \geq 0 .
\end{gathered}
$$

Substituting $N=2$ and $n=2$ into Eqs. (38) and (39) gives:

$$
\frac{(h c \alpha+\theta+c \theta)^{2}}{2(1+c)(-2-2 c+\alpha)^{2}}>0 \text { and } \frac{\alpha(2+2 c+3 \alpha)(h c \alpha+\theta+c \theta)^{2}}{8(1+c)^{2}(1+c-\alpha)(1+c+\alpha)^{2}}>0 .
$$

Clearly, both conditions are fulfilled and, hence, two countries cooperate.

Then we analyze the stability of a two-country coalition if $N>2$. Substituting $n=2$ into Eq. (38) gives:

$$
\frac{\left((1+c)^{2} N^{4}-2(1+c) N^{2}\left(N+N^{2}-4\right) \alpha+(N-2)(N-1)(2+N(5+N)) \alpha^{2}\right)(h c \alpha+\theta+c \theta)^{2}}{2(1+c-\alpha)(N(1+c-\alpha)+\alpha)^{2}(2 \alpha+N(N(1+c-\alpha)+\alpha))^{2}} \geq 0 .
$$

Internal stability is fulfilled if $c \geq-1+\frac{\left(N^{2}+N-4\right) \alpha}{N^{2}}+\frac{2 \alpha \sqrt{3+(N-3) N}}{N^{2}}$. We note that the right side of the inequality increases in $\alpha$ if $N \geq 4$ and decreases in $N$ if $N \geq 5$. Substituting $n=2$ into Eq. (39) gives:

$$
\frac{4 N^{3} \alpha\left((1+c)\left(N^{2}-N\right)-\left(N^{2}-2 N-3\right) \alpha\right)(h c \alpha+\theta+c \theta)^{2}}{(1+c-\alpha)(2 \alpha+N(N(1+c-\alpha)+\alpha))^{2}(6 \alpha+N(N(1+c-\alpha)+\alpha))^{2}}>0,
$$

which implies that external stability of $n=2$ is always fulfilled. This implies that a three-country coalition is not internally stable. We further show that coalitions of size $n \geq 3$ are not internally stable. Numerical proof with Mathematica software package: 


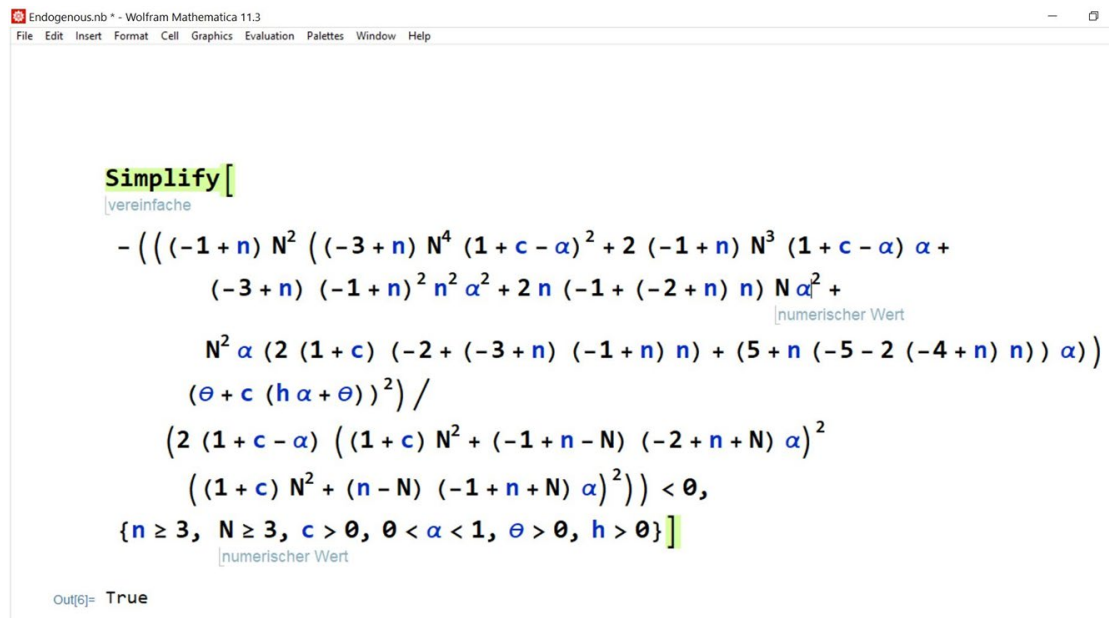

The last line contains parameter values to be substituted in the inequality above. The result indicates "True", that is the internal stability for the given parameterization is never fulfilled. Hence stable coalitions of size $n \geq 3$ do not exist. If $N \geq 3$ either $n=2$ or $n=1$ is stable in equilibrium. From that we note that incentives to cooperate do not increase in $\alpha$ and $\theta$.

Aggregate payoffs are $\Pi_{a}=n \pi_{s}+(N-n) \pi_{f}$. By inserting $n=0$ into Eq. (29) we get the aggregate net benefit of the non-cooperative case:

$$
\Pi_{u}=-\frac{N((-h N+h(N-1) \alpha+(N-1) \theta)(h(1+c) N+h(c-1)(N-1) \alpha+(1+c)(N-1) \theta))}{2(N(1+c-\alpha)+\alpha)^{2}},
$$

and by inserting $n=N$ in Eq. (28) we get the net benefit of the social optimal case:

$$
\Pi_{o}=\frac{N h^{2}}{2+2 c} .
$$

Inserting the net benefits of the different scenarios into Eq. (21) and assuming $n=2$ we obtain:

$$
C G I=\frac{\left(\begin{array}{c}
4(1+c) N^{4}(1+c-\alpha)^{2}-4(1+c) N^{2}(1+c-\alpha) \alpha+4(1+c) \alpha^{2} \\
-2(1+c) N \alpha^{2}+2(1+c) N^{3}\left(-3(1+c)^{2}+8(1+c) \alpha-5 \alpha^{2}\right)
\end{array}\right)}{\left(\begin{array}{c}
H^{6}(1+c-\alpha)^{3}-2 H^{5}(1+c-2 \alpha)(1+c-\alpha)^{2}+H^{4}(1+c-\alpha)\left((1+c-\alpha)^{2}+\alpha^{2}\right) \\
-2 H^{3}(3+3 c-4 \alpha)(1+c-\alpha) \alpha+H^{2}(4+4 c-7 \alpha)(1+c-\alpha) \alpha-4 H(1+c-\alpha) \alpha^{2}
\end{array}\right)} .
$$

We note from Eq. (45) that the CGI is invariant in $h$ and $\theta$ and that $\lim _{N \rightarrow \infty} C G I=0$ if the number of countries interconnected is very large. 


\section{Proof of Proposition 5}

Inserting Eqs. (28) and (29) into the altered internal stability function $\pi_{s}(n)+g(n-1)-\pi_{f}(n-1) \geq 0$ and substituting $n=N$ we get:

$$
\frac{1}{2}(N-1)\left(2 g-\frac{\left((1+c)(N-3) N^{2}+4(N-1) \alpha\right)(h c \alpha+\theta+c \theta)^{2}}{(1+c)(1+c-\alpha)(N(N+c N-2 \alpha)+2 \alpha)^{2}}\right) \geq 0 .
$$

We note that Eq. (46) is strictly increasing in $g$ and hence internal stability is fulfilled if $g \geq \frac{\left((1+c)(N-3) N^{2}+4(N-1) \alpha\right)(h c \alpha+\theta+c \theta)^{2}}{2(1+c)(1+c-\alpha)(N(N+c N-2 \alpha)+2 \alpha)^{2}} \equiv A$. If the club benefits are large enough, the grand coalition can be stable. By multiplying the condition for $g$ by $(N-1)$ we get the amount of club benefits $E_{s}(N)=g(N-1)$ which are needed to stabilize the grand coalition. The condition then becomes $E_{s}(N) \geq A(N-1)$. Putting the necessary club benefits in relation with the public benefits given by Eq. (24) we get:

$$
\begin{aligned}
& \gamma \equiv \frac{E_{s}(N)}{H_{s}(N)} \geq \frac{(1+c)(N-1)\left((1+c)(N-3) N^{2}+4(N-1) \alpha\right)(h c \alpha+\theta+c \theta)^{2}}{(1+2 c)(1+c-\alpha) \alpha\left(h(1+c) N^{2}-2 h(N-1) \alpha\right)^{2}} . \\
& \partial \gamma / \partial \theta=\frac{2(1+c)^{2}(N-1)\left((1+c)(N-3) N^{2}+4(N-1) \alpha\right)(h c \alpha+\theta+c \theta)}{(1+2 c)(1+c-\alpha) \alpha\left(h(1+c) N^{2}-2 h(N-1) \alpha\right)^{2}}>0 \text { and } \partial \gamma / \partial h=- \\
& \frac{2(1+c)^{2}(N-1)\left((1+c)(N-3) N^{2}+4(N-1) \alpha\right) \theta(h c \alpha+\theta+c \theta)}{h^{3}(1+2 c)(1+c-\alpha) \alpha(N(N+c N-2 \alpha)+2 \alpha)^{2}}>0 .
\end{aligned}
$$

\section{Proof of Lemma 1}

The maximization problem of the free riders is given by:

$$
\max _{q_{f}} \pi_{f}=\alpha b \bar{q}+(1-\alpha) b q_{f}-\frac{1}{2} c q_{f}^{2}-\theta\left(q_{f}-\bar{q}\right) .
$$

The corresponding reaction function is given by:

$$
q_{f}^{*}=\frac{b(N+\alpha-N \alpha)+\theta-N \theta}{c N}
$$

The maximization problem of the signatories is given by:

$$
\max _{q_{s}} \pi_{s}=\alpha b\left(\frac{n q_{s}+(N-n) q_{f}}{N}\right)+(1-\alpha) b q_{s}+g(n-1)-\frac{1}{2} c q_{s}^{2}-\theta\left(q_{s}-\frac{n q_{s}+(N-n) q_{f}}{N}\right)
$$

The corresponding reaction function is given by:

$$
q_{s}^{*}=\frac{b(N+n \alpha-N \alpha)+(n-N) \theta}{c N} .
$$


$\partial q_{s}^{*} / \partial n>0$ and $\partial q_{f}^{*} / \partial n=0$ and, hence, $q_{s}^{*}>\bar{q}>q_{f}^{*}=q_{c}$. Inserting equilibrium effort levels given by Eqs. (49) and (51) into Eqs. (48) and (50), we get the equilibrium net benefits given by:

$$
\pi_{s}=\frac{b^{2}\left(N^{2}+(n-N)(N+n-2) \alpha^{2}\right)+2 b(n-N)(N+n-2) \alpha \theta+(n-N)(N+n-2) \theta^{2}}{2 c N^{2}}
$$

and

$$
\begin{aligned}
& \pi_{f}=\frac{b^{2}\left(N^{2}-\left(-2(n-1) n+(N-1)^{2}\right) \alpha^{2}\right)-2 b\left(-2(n-1) n+(N-1)^{2}\right) \alpha \theta-\left(-2(n-1) n+(N-1)^{2}\right) \theta^{2}}{2 c N^{2}} . \\
& \partial \pi_{s} / \partial n=\frac{(n-1)(b \alpha+\theta)^{2}}{c N^{2}} \text { and } \partial \pi_{f} / \partial n=\frac{(2 n-1)(b \alpha+\theta)^{2}}{c N^{2}}>0 \text { and } \pi_{f}>\bar{\pi}>\pi_{s}>\pi_{c} .
\end{aligned}
$$

\section{Proof of Proposition 6}

Substituting the net benefits given by Eqs. (52) and (53) into Eq. (20) we receive the relevant stability conditions. First, we solve the internal stability condition $\pi_{s}(n) \geq \pi_{f}(n-1)$ for $n$, which yields that internal stability is fulfilled for:

$$
3+\frac{2 c g N^{2}}{(b \alpha+\theta)^{2}} \geq n \geq 1 .
$$

Then, we solve the external stability condition $\pi_{f}(n) \geq \pi_{s}(n+1)$ for $n$, which yields that the external stability is fulfilled for:

$$
n \geq 2+\frac{2 c g N^{2}}{(b \alpha+\theta)^{2}} .
$$

Hence, both conditions are fulfilled simultaneously for:

$$
3+\frac{2 c g N^{2}}{(b \alpha+\theta)^{2}} \geq n \geq 2+\frac{2 c g N^{2}}{(b \alpha+\theta)^{2}} .
$$

If $g=0$, coalitions of size $n \in\{2,3\}$ are stable. We note from Eq. (56) that $\partial n / \partial c$ and $\partial n / \partial N>0$ and that $\partial n / \partial \alpha$ and $\partial n / \partial \theta<0$. Both sides of the interval grow proportionally in all exogenous parameters. Hence, it is sufficient to analyze the internal stability to determine the stable size of a coalition. Solving the internal stability with respect to $g$ we get:

$$
g \geq \frac{(n-3)(b \alpha+\theta)^{2}}{2 c N^{2}} .
$$

This equation determines the necessary size of $g$ in order to stabilize a coalition of size $n$. If we substitute $N$ into Eq. (57) we get the value of $g$ in order to stabilize the grand coalition. By multiplying this by $(N-1)$ we get the amount of club benefits $E_{s}(N)$ which are needed to stabilize the grand coalition. Putting the necessary club benefits in relation with the public benefits $H_{s}(N)$ we get: 


$$
\begin{gathered}
\gamma \equiv \frac{E_{s}(N)}{H_{s}(N)}=\frac{(N-3)(N-1)(b \alpha+\theta)^{2}}{2 b^{2} N^{2} \alpha} . \\
\partial \gamma / \partial \theta=\frac{(N-3)(N-1)(b \alpha+\theta)}{b^{2} N^{2} \alpha}>0, \partial \gamma / \partial N=\frac{(2 N-3)(b \alpha+\theta)^{2}}{b^{2} N^{3} \alpha}>0 \text { and } \partial \gamma / \partial b=-\frac{(N-3)(N-1) \theta(b \alpha+\theta)}{b^{3} N^{2} \alpha}<0 .
\end{gathered}
$$
Aggregate net benefits are given by:

$$
\Pi_{a}=\frac{b^{2}\left(N^{3}-(N-n)\left(-n^{2}+(N-1)^{2}+n N\right) \alpha^{2}\right)-2 b(N-n)\left(-n^{2}+(N-1)^{2}+n N\right) \alpha \theta}{-(N-n)\left(-n^{2}+(N-1)^{2}+n N\right) \theta^{2}}
$$

By inserting $n=0$ into Eq. (59) we get the aggregate net benefit of the noncooperative case:

$$
\Pi_{u}=-\frac{(-b N+b(N-1) \alpha+(N-1) \theta)(b(N+(N-1) \alpha)+(N-1) \theta)}{2 c N},
$$

and by inserting $n=N$ in Eq. (59) we get the net benefit of the social optimal case:

$$
\Pi_{o}=N\left(\frac{b^{2}}{2 c}+g(N-1)\right)
$$

Inserting Eqs. (59), (60) and (61) into Eq. (21) we obtain the CGI given by:

$$
C G I=\frac{(n-1) n(2 N-n-1)(b \alpha+\theta)^{2}}{(N-1) N\left(2 c g N^{2}+(N-1)(b \alpha+\theta)^{2}\right)} .
$$

If $g=0$ we substitute $n=2$ and $n=3$ as stable solutions into Eq. (62) and get:

$$
C G I(2)=\frac{4 N-6}{N(N-1)^{2}} \text { and } C G I(3)=\frac{12(N-2)}{N(N-1)^{2}}
$$

We note that Eq. (63) does not depend on $b, \alpha, c$ and $\theta$. If $g>0$ we note from Eq. (62) that the CGI depends on all parameters and that the CGI always converges to zero if $N \rightarrow \infty$.

Author Contributions The initial research design has been jointly developed by Michael Abendschein and Harry Gölz, including in particular the development of the model set-up. Both of them have also contributed to updates and revisions of the research design as well as drafting of the manuscript. Harry Gölz has to a major extent carried out the mathematical analyses with a particular focus on propositions and proofs. He has also to a minor degree contributed to the interpretation of the achieved results within the framework of the research project. Michael Abendschein has to a major extent interpreted the mathematical results with a view on the relation to financial regulation and cooperation. He has to a minor extent contributed to proofs and further mathematical analyses.

Funding Open Access funding enabled and organized by Projekt DEAL. A travel grant for a presentation at a conference from the Universitätsgesellschaft Osnabrück is acknowledged. 
Open Access This article is licensed under a Creative Commons Attribution 4.0 International License, which permits use, sharing, adaptation, distribution and reproduction in any medium or format, as long as you give appropriate credit to the original author(s) and the source, provide a link to the Creative Commons licence, and indicate if changes were made. The images or other third party material in this article are included in the article's Creative Commons licence, unless indicated otherwise in a credit line to the material. If material is not included in the article's Creative Commons licence and your intended use is not permitted by statutory regulation or exceeds the permitted use, you will need to obtain permission directly from the copyright holder. To view a copy of this licence, visit http://creativecommons.org/licenses/by/4.0/.

\section{References}

Acharya VV (2003) Is the International Convergence of Capital Adequacy Regulation Desirable? J Financ 58(6):2745-2781. https://doi.org/10.1046/j.1540-6261.2003.00621.x

Agénor PR, Pereira da Silva L (2018) Financial spillovers, spillbacks, and the scope for international macroprudential policy cooperation, BIS Working Paper No. 97

Allen F, Gale D (2004) Competition and Financial Stability, J Money Credit Banking 36(3):453480. https://www.jstor.org/stable/i371342

Barrett S (1994) Self-enforcing International Environmental Agreements. Oxford Econ Pap 46:878894. https://www.jstor.org/stable/2663505

Barth JR, Caprio G, Levine R (2006) Rethinking Banking Regulation: Till Angels Govern. Cambridge University Press, New York

Beck T, Silva-Buston C, Wagner W (2019) The Economics of Supranational Bank Supervision, CEPR Discuss Pap No. DP12764

Bergstrom T, Blume L, Varian H (1986) On the Private Provision of Public Goods. J Public Econ 29:2549. https://doi.org/10.1016/0047-2727(86)90024-1

Buck F, Schliephake E (2013) The regulator's trade-off: Bank supervision vs. minimum capital. J Bank Finance 37:4584-4598. https://doi.org/10.1016/j.jbankfin.2013.04.012

D’Aspremont CA, Jacquemin J, Gabszewicz J, Weymark JA (1983) On the stability of collusive price leadership. Can J Econ 16:17-25. https://doi.org/10.2307/134972

Degryse H, Ongena S (2005) Distance, Lending Relationships and Competition. J Finance 60(1):231266. https://doi.org/10.1111/j.1540-6261.2005.00729.x

De Jonghe O, Dewachter H, Ongena S (2020) Bank Capital (Requirements) and Credit Supply: Evidence from Pillar 2 Decisions, J Corporate Finance 60. https://doi.org/10.1016/j.jcorpfin.2019.101518

Dell'Ariccia G, Marquez R (2001) Competition among Regulators. Int Monetary Fund Working Paper $\mathrm{WP} / 01 / 73$

Dell'Ariccia G, Marquez R (2006) Competition among Regulators and Credit Market Integration. J Financ Econ 79(2):401-430. https://doi.org/10.1016/j.jfineco.2005.02.003

Demirgüç-Kunt A, Detragiache E (2002) Does deposit insurance increase banking system stability? An Empirical Investigation. J Monetary Economics 49(7):1373-1406. https://doi.org/10.1016/S03043932(02)00171-X

Eldridge DS, Ryoo HH, Wieneke A (2015) Bank Capital Regulation with Asymmetric Countries. Economic Record 91(292):79-90. https://doi.org/10.1111/1475-4932.12152

European Commission (2017) EU equivalence decisions in financial services policy: an assessment, Commission Staff Working Document

Eyckmans J, Finus M (2006) Coalition formation in a global warming game: how the design of protocols affects the success of environmental treaty-making. Nat Resour Model 19(3):323-358. https://doi. org/10.1111/j.1939-7445.2006.tb00184.x

Financial Action Task Force (FATF) (2020), International Standards on Combating Money Laundering and the Financing of Terrorism and Proliferation.

Finus M, Rübbelke DTG (2013) Public Good Provision and Ancillary Benefits: The Case of Climate Agreements. Environ Resource Econ 56(2):211-226. https://doi.org/10.1007/s10640-012-9570-6

Gaspar V, Schinasi G (2010) Financial Stability and Policy Cooperation, Occasional Paper 1/2010, Bank of Portugal

Gehrig T (2014) SOAS Centenary Lecture on International Banking Supervision 
Goodhart C (2011) The Basel Committee on Banking Supervision: a history of the early years, 19741997. Cambridge University Press, Cambridge

Gosh A, Ostry J, Qureshi M (2017) Managing the tide: how do emerging markets respond to capital flows?, IMF Working Paper No. 17/69

Hardy DC, Nieto MJ (2011) Cross-Border Coordination of Prudential Supervision and Deposit Guarantees. J Financ Stab 7(3):155-164. https://doi.org/10.1016/j.jfs.2010.01.003

Hauswald R, Marquez R (2006) Competition and Strategic Information Acquisition in Credit Markets. Rev Financ Stud 19(3):967-1000. https://doi.org/10.1093/rfs/hhj021

Hoel M, Schneider K (1997) Incentives to Participate in an International Environmental Agreement. Environ Resource Econ 9:153-170. https://doi.org/10.1023/A:1026486715088

Holthausen C, Rønde T (2005) Cooperation in International Banking Supervision, Center Econ Policy Res Discuss Pap Series No. 4990

Kara G (2016) Systemic risk, international regulation and the limits of coordination. J Int Econ 99:192222. https://doi.org/10.1016/j.jinteco.2015.11.007

Kaul I, Grunberg I, Stern M (eds) (1999) Global Public Goods: International Cooperation in the 21st Century. Oxford University Press, New York

Korinek A (2017) Currency wars or efficient spillovers? A general theory of international policy cooperation, IMF Working Paper No. 17/25

Nordhaus W (2015) Climate Clubs: Overcoming Free-riding in International Climate Policy. Am Econ Rev 105(4):1339-1370. https://doi.org/10.1257/aer.15000001

Olson M, Zeckhauser R (1966) An Economic Theory of Alliances. Rev Econ Stat 48(3):266-279. https:// doi.org/10.2307/1927082

Park S, Kim Y-H (2018) International Policy Coordination for Financial Regime Stability under Crossborder Externalities. J Bank Finance 97:177-188. https://doi.org/10.1016/j.jbankfin.2018.10.002

Schoenmaker D (2011) The Financial Trilemma. Econ Lett 111:57-59. https://doi.org/10.1016/j.econlet. 2011.01.010

Sinn HW (2003) Risk Taking, Limited Liability, and the Competition of Bank Regulators, FinanzArchiv: Public Finance. Analysis 59(3):305-329

Uluc A, Wieladek T (2017) Capital requirements, risk shifting and the mortgage market. Eu Central Bank Working Pap Series No 2061

VanHoose D (2016) Should Financial Regulators Engage in International Policy Coordination? IEEP 13(2):319-338. https://doi.org/10.1007/s10368-015-0311-5

White LJ (1994) On the International Harmonization of Bank Regulation, Oxford Review of Economic Policy 10(4):94-105. https://www.jstor.org/stable/23606347

Publisher's Note Springer Nature remains neutral with regard to jurisdictional claims in published maps and institutional affiliations. 